\title{
Comentários sobre o juízo aprovativo das contas pelo Tribunal de Contas baiano
}

Notes on the approval of accounts by the Bahia Court of Accounts

\section{Inaldo da Paixão Santos Araújo ${ }^{1}$}

\section{RESUMO}

Os tribunais de contas do Brasil têm a missão constitucional de exercer o controle externo da administração pública, zelando pela coisa pública, especialmente o patrimônio e o adequado emprego dos recursos públicos. Nessa perspectiva, desempenham importante papel emitindo decisões em processos de controle externo instruídos, dentre outros informes, com opinativos e comentários técnicos decorrentes de exames auditoriais procedidos à luz das normas de auditoria, o que proporciona segurança jurídica e objetividade técnica às opiniões conclusivamente externadas pelas unidades técnicas. Tendo por base o arcabouço normativo que disciplina a atividade-fim das cortes de contas brasileiras, este artigo apresenta um panorama comparativo entre as interpretações e deliberações de cunho decisório conferidas pelos órgãos julgadores dos tribunais de contas (atividade judicante). Apresentam-se, com isso, os graus de aproximação e de distanciamento entre os fundamentos fáticos e jurídico-normativos invocados nas decisões de mérito proferidas especialmente no Tribunal de Contas do Estado da Bahia, e aqueles levados às peças informativas que subsidiaram os julgamentos, notadamente relatórios técnicos.

Palavras-Chave: Auditoria. Controle Externo. Função Judicante. Processos de Contas.

1 Conselheiro-corregedor do Tribunal de Contas do Estado da Bahia. Mestre em Contabilidade. Professor. Escritor. E-mail: inaldo_paixao@hotmail.com 


\section{ABSTRACT}

The Brazilian courts of accounts have as constitutional mission to exercise external control over public administration, taking care of public affairs, especially the assets and the appropriate use of public resources. As such, they play an important role in issuing decisions in external control processes, which are structured, among other reports, with opinions and technical comments arising from audits following auditing standards, which provides legal certainty and technical objectivity to opinions conclusively provided by technical units. Based on the normative framework that governs the core activity of the Brazilian courts of accounts, this paper presents a comparative panorama between the interpretations and deliberations of a decisive nature conferred by decision-making bodies of the courts of accounts (judicial activity), and with it, the degrees of approximation between factual and legal-normative foundations invoked in decisions on merits, especially in the Court of Auditors of the State of Bahia, and the bases used in informational pieces that support trials, most notably technical reports.

Keywords: Auditing. External Control. Judicial Function. Account Processes.

Recebido: 07-12-2020

Aprovado: 11-12-2020

\section{DAS QUESTÕES INICIAIS}

Ao longo do meu trabalho como julgador de contas públicas, muito se discute sobre as advertências possíveis no juízo aprovativo, especialmente no que tange à imposição de restrições.

Considerando pesquisa realizada nos 33 portais na rede mundial de computadores dos tribunais de contas brasileiros, que teve como pilar os normativos jurídicos (leis orgânicas e regimentos internos) dessas casas de controle, foi possível mapear o posicionamento normativo previsto de 
cada instituição em relação às decisões proferidas em processos de prestação de contas.

As manifestações previstas em sede de processos de prestação de contas nos tribunais de contas podem ser assim apresentadas ${ }^{2}$ :

a) Na região Centro-Oeste: composta por seis Cortes de Contas, as decisões para os processos de prestações de contas adotam os seguintes direcionamentos:

- 5 Instituições: Regulares, regulares com ressalva ou irregulares.

- 1 Instituição: Regulares, regulares com recomendações e/ou com determinações legais, irregulares ou iliquidáveis.

Sintetizando: $83 \%$ são regulares, regulares com ressalva ou irregulares e $17 \%$ se posiciona por regulares, regulares com recomendações e/ ou com determinações legais, irregulares ou iliquidáveis.

b) Na região Nordeste: composta por 10 cortes de contas, as decisões para os processos de prestações de contas adotam os seguintes direcionamentos:

- sete instituições: regulares, regulares com ressalva ou irregulares;

- duas instituições: regulares, regulares com ressalvas, irregulares e/ou iliquidáveis;

- uma instituição: aprovar, aprovar com observações, recomendações ou ressalvas, desaprovar com imputação de débito.

Sintetizando: $70 \%$ são regulares, regulares com ressalva ou irregulares; 20\% são regulares, regulares com ressalvas, irregulares e/ou iliquidáveis; e 10\% aprovar, aprovar com observações, recomendações ou ressalvas, desaprovar.

c) Na região Norte: composta por oito cortes de contas, as decisões para os processos de prestações de contas adotam os seguintes direcionamentos:

- sete instituições: regulares, regulares com ressalva ou irregulares;

- uma instituição: regulares, regulares com ressalvas, ou irregulares e iliquidáveis.

O resultado completo da pesquisa realizada em 20 de maio de 2020 se encontra no anexo A. 
Sintetizando: $88 \%$ são regulares, regulares com ressalva ou irregulares; $12 \%$ são regulares, regulares com ressalvas, ou irregulares e iliquidáveis.

d) Na região Sudeste: composta por seis cortes de contas, as decisões para os processos de prestações de contas adotam os seguintes direcionamentos:

- quatro instituições: regulares, regulares com ressalva ou irregulares;

- uma instituição: regulares, regulares com ressalva, irregulares ou iliquidáveis;

- uma instituição: definitiva; terminativa.

e) Na região Sul: composta de três cortes de contas, a decisão para processo de prestações de contas seguem as mesmas condições: regulares, regulares com ressalva ou irregulares.

Em um panorama geral, nas 33 cortes de contas brasileiras, as decisões em processo de prestação de contas não são uniformes e seguem as seguintes condições:

- uma instituição (TCE-BA): aprovar, aprovar com observações, recomendações ou ressalvas, desaprovar;

- uma instituição (TCM-SP): definitiva; terminativa;

- uma instituição (TCE-MT): regulares, regulares com recomendações e/ou determinações legais, ou irregulares;

- quatro instituições (TCE-ES, TCE-PB, TCM-BA E TCM-PA): regulares, regulares com ressalvas, irregulares e/ou iliquidáveis;

- 26 instituições (TC-DF, TCE-AC, TCE-AL, TCE-AM, TCE-AP, TCE-CE, TCE-GO, TCE-MA, TCE-MG, TCE-MS, TCE-PA, TCE-PE, TCE-PI, TCE-PR, TCE-RJ, TCE-RN, TCE-RO, TCE-RR, TCE-RS, TCE -SC, TCE-SE, TCE-SP, TCE-TO, TCM-GO, TCM-RJ, TCU): regulares, regulares com ressalva ou irregulares.

Portanto pode-se concluir que, no universo analisado:

- $78 \%$ das cortes de contas brasileiras julgam os processos de contas como: regulares, regulares com ressalva ou irregulares; 
- $12 \%$ das cortes de contas brasileiras julgam os processos de contas como: regulares, regulares com ressalvas, irregulares e/ou iliquidáveis;

- $3 \%$ das cortes de contas brasileiras julgam os processos de contas como: aprovar, aprovar com observações, recomendações ou ressalvas, desaprovar com imputação de débito;

- $3 \%$ das cortes de contas brasileiras julgam os processos de contas como: definitiva; terminativa.

\section{DA ANÁLISE ESPECÍFICA DA CORTE DE CONTAS BAIA- NA E OS FUNDAMENTOS AUDITORIAIS}

De logo, vale destacar o que dispõe o art. 122 da Resolução n $^{\circ} 18$, de 29 de junho de 1992, que aprovou o Regimento Interno do Tribunal de Contas do Estado da Bahia:

Art. 122. O Tribunal de Contas julgará quite, em crédito ou em débito o responsável por prestação ou tomada de contas, podendo ainda, a seu critério, de relação às contas:

I - aprovar, quando expressem, de forma clara e objetiva, a exatidão dos demonstrativos contábeis, a legalidade, a legitimidade, a economicidade, a moralidade e a razoabilidade dos atos de gestão do responsável;

II - aprovar com observações, recomendações ou ressalvas, quando evidenciem impropriedades ou qualquer outra falha de natureza formal, ou ainda, a prática de ato de gestão que não configure gravidade e que não represente injustificado dano ao erário ou ao patrimônio público;

III - desaprovar, quando configuradas, quaisquer das seguintes ocorrências:

a) grave infração à norma legal ou regulamentar de natureza contábil, financeira, orçamentária, operacional, patrimonial ou de licitação;

b) culposa aplicação antieconômica de recursos públicos;

c) injustificado dano ao erário ou ao patrimônio público;

d) desfalque, desvio de dinheiro, bens e valores públicos;

IV - arquivar, quando iliquidáveis, em caso fortuito ou de força maior (Grifo nosso). 
É sabido e por demais consabido que as funções constitucionais dos tribunais de contas brasileiros (opinativa, judicante, fiscalizatória, sancionatória, de registro e consultiva), via de regra carece, para sua completa efetividade, do devido suporte auditorial. Como emitir um parecer prévio sobre as contas governamentais, como julgar uma prestação ou uma tomada de contas sem uma análise auditorial prévia?

Não é por outra razão que a Lei Orgânica do Tribunal de Contas do Estado da Bahia (TCE-BA) estabelece em seu artigo $9^{\circ}$ que:

O parecer prévio sobre as contas do Chefe do Poder Executivo, bem como o julgamento das contas dos administradores e demais responsáveis por dinheiro, bens e valores públicos e daqueles que derem causa a perda, extravio ou outra irregularidade de que resulte prejuízo e dano ao erário, devem estar fundamentados nas respectivas auditorias.

Porém esse dispositivo não significa dizer que o posicionamento auditorial seja vinculante, determinante para o bem decidir de um conselheiro ou mesmo da decisão terminativa do plenário, mas, se assim não o for, a posição contrária carece dos devidos fundamentos.

Isso posto, é mister salientar, de logo, que o TCE-BA, enquanto órgão de julgamento de contas, é ambivalente (posto que audita/fiscaliza e também julga as contas) e tem, na sua estrutura normativa positivada, regramentos oriundos de normas de auditoria, dentre as quais destaco o nível 3 das Normas Brasileiras de Auditoria do Setor Público (NBASP), a que está obrigado também a observar.

Com efeito, nesse particular, ao proceder ao exame das demonstrações contidas nas prestações de contas, poderá o auditor dessa casa de auditoria emitir um relatório conclusivo pela regularidade, chamado de parecer limpo, quando não forem identificadas ocorrências relevantes de não conformidade (Norma 193 da NBASP).

Contudo, nos casos de ocorrências relevantes de não conformidade, a depender da extensão destes apontamentos, poderá resultar em uma 
opinião com ressalvas, no suposto de os desvios de conformidade serem relevantes, porém não generalizados (NBASP 194, alínea “a” item “i”).

Também poderá o auditor, em sua peça conclusiva, expressar uma opinião adversa (se os desvios de conformidade forem relevantes e generalizados (NBASP 194, alínea "a" item "ii"). Nesses casos, há motivos para dar ensejo ao juízo reprovativo, com ou sem caracterização de dano ou débito ao erário, com a possibilidade, inclusive, de apenar a conduta com multa nos termos da legislação específica.

Há, ademais, casos em que a equipe de auditoria opta pela negativa de opinião, situações em que se configura limitação de escopo, dependendo da sua extensão, que resulta em uma abstenção de opinião, no suposto de os auditores não conseguirem obter evidência de auditoria suficiente e apropriada sobre a conformidade com as normas, e os possíveis efeitos são relevantes e generalizados (NBASP 194, alínea "b" item "iv").

Sobre as recomendações, diante dos apontamentos, dos achados de Auditoria, a citada norma reza: "126. O auditor deve fornecer recomendações construtivas que sejam capazes de contribuir significativamente para sanar as deficiências ou problemas identificados pela auditoria, sempre que relevante e permitido pelo mandato da EFS".

Dito isso, reafirmo que é me valendo destas lentes das normas auditoriais, e que nossos diligentes auditores observam e declaram que observam, que faço - e devo fazer - a exegese dos dispositivos do art. 122, inciso II, do nosso Regimento Interno.

Clamo atenção para o fato de que o disposto no Regimento Interno está alinhado com as NBASP, que estabelece que merecem ressalvas, quando ocorrerem fatos relevantes de não conformidade, se os desvios de conformidade forem relevantes, mas não generalizados (NBASP 194, alínea "a" item "i").

Nada obstante, retomando a reflexão, quanto ao que literalmente dispõe o art. 122, inciso II, na medida em que prevê a possibilidade desta Entidade de Fiscalização Estadual aprovar com observações, recomenda- 
ções ou ressalvas, vale ser dada a público a interpretação do professor e mestre em Linguística José Lúcio de Farias. Ao ser defrontado a emitir uma opinião sobre a que se referiam as citadas "impropriedades ou qualquer outra falha de natureza formal, ou ainda, a prática de ato de gestão que não configure gravidade e que não represente injustificado dano ao erário ou ao patrimônio público", assim se manifestou o especialista: "é claro que se refere tanto a ressalvas, quanto a observações e recomendações, que o TCE julgar necessárias. No final do caput do artigo, dir-se-ia com mais propriedade: com relação às contas...".

Assim, com base na vida e vivência de auditor e também de julgador de contas, com o esteio firme nas normas de auditoria, peço vênia para expor e firmar a tese de que o Tribunal de Contas do Estado da Bahia poderá aprovar as Contas com observações, segundo os achados auditoriais, recomendações, estas mais apropriadas para as auditorias operacionais e as integradas, assim como poderá sugerir ressalvas. Todas essas situações ensejadoras de observações, recomendações e ressalvas, a depender da gradação, ocorrerão quando houver impropriedades, qualquer outra falha de natureza formal ou, ainda, pela prática de ato de gestão que não configure gravidade e que não represente injustificado dano ao erário ou ao patrimônio público.

Faço ainda mais cristalino o que penso...

As falhas de natureza formal, ou a prática de ato de gestão que não configure gravidade e que não represente dano ao erário ou ao patrimônio público, podem ser objeto de observações, recomendações e ressalvas. Como ainda não há definição clara e objetiva sobre a gradação, quem há de estabelecer a dosimetria é cada julgador, sujeitando-se sempre à vontade soberana do plenário.

Se nada disso fosse o bastante, necessário se faz responder à luz do bom direito à seguinte indagação: observações, recomendações e ressalvas no controle das contas públicas no âmbito do TCE-BA: há distinção normativa?

Para bem responder, é preciso saber bem interpretar a norma. 


\section{DO BEM INTERPRETAR}

É indubitável a importância da escrita e da leitura na vida dos seres humanos. Não por acaso, há algo no ato de grafar palavras que muito me intriga. Um texto bem escrito é capaz de nos emocionar, de nos apresentar épocas que não vivemos, de nos transportar para mundos, reais ou imaginários, em que nunca estivemos.

A escrita é, sem dúvida, a primeira memória artificial criada pelo homem. Entretanto essa tecnologia de comunicação inventada pelos sumérios, na Mesopotâmia (3.500 a.C.), pode revelar um lado sombrio, sobretudo na fixação de normas que regem a sociedade. Há leis muito claras e justas, todavia, em diversas peças jurídicas, a redação que deveria dar suporte às normas sociais descreve, não raro, o caminho da obscuridade, que faz o leitor se perder rapidamente em cláusulas, artigos e incisos incompreensíveis.

Pode-se considerar que há dois grandes grupos de leis: as leis naturais e as leis sociais. Como leis naturais conhecemos as da física, da química e da biologia. Algumas delas são consideradas imutáveis, até que um grupo de cientistas quebre seus paradigmas. Há ainda o grupo de leis sociais, dentre as quais se destacam as do direito, estas muito mais mutáveis do que as leis naturais.

As leis do direito têm sua gênese em um mandamento constitucional atrelado a um grande contrato social. Elas se mantêm como leis estabelecidas pelos poderes vigentes, considerando-se qualquer regime de governo. Notemos que o próprio direito fortaleceu ações degradantes na história da humanidade ao dar seu lastro de legalidade a regimes totalitários como o fascismo, nazismo, entre outros.

Entretanto, se no ramo da ciência podemos validar uma norma com a experimentação, a prática e a pesquisa, nas leis do direito surge um elemento fundamental, que é a interpretação. As normas se sustêm não apenas pelo que está escrito, mas pela interpretação adequada feita pelos 
operadores da lei, sejam eles magistrados, advogados ou conselheiros dos tribunais de contas.

Não é, portanto, prudente considerar uma lei cuja interpretação esteja sujeita a casos particulares. $O$ consenso sobre a norma deve sempre rimar com bom senso. E, neste contexto, saber interpretar ganha o mesmo peso de saber redigir. Sendo assim, a interpretação precisa, lúcida e justa depende de uma norma bem escrita, clara e objetiva. A redação concisa de uma lei, um ato, uma resolução ou qualquer outra peça de respaldo jurídico evita subterfúgios ou mesmo análises que prejudiquem ou conduzam a interesses momentâneos. Já no que concerne à interpretação, serve de alerta para imprecisões ou ambiguidades.

Em arremate, aos intérpretes das leis, compete que sejam fiéis aos predicados básicos da boa interpretação, a exemplo de uma análise aprofundada das peças jurídicas. Lembremos o que professou o filósofo Friedrich Nietzsche (1887): "Não existem fatos, apenas interpretações". Que a força da interpretação faça justiça e garanta a dignidade das leis e, principalmente, dos seres humanos.

\section{DO ART. 122 DO REGIMENTO INTERNO DO TRIBUNAL DE CONTAS DO ESTADO DA BAHIA}

Como dito no art. 122 do Regimento Interno do TCE-BA, a critério técnico se poderão aprovar as contas (inciso I), desaprová-las (inciso III) ou aprová-las "com observações, recomendações e ressalvas, quando evidenciem impropriedades ou qualquer outra falha de natureza formal, ou ainda, à prática de ato de gestão que não configure gravidade e que não represente injustificado dano ao erário ou ao patrimônio público" (inciso II).

$\mathrm{O}$ art. 24 da Lei Orgânica do TCE-BA (Lei Complementar $\left.n^{o} 5 / 1991\right)$ prevê, no mesmo sentido, que o Tribunal poderá aprovar as contas "fazendo observações, recomendações ou ressalvas, quando for o caso" (inciso I). 
Em vista desses enunciados normativos, a questão é saber se, no exercício das atribuições do TCE baiano, há distinção possível entre as observações, recomendações e ressalvas que caibam ser feitas na ação de controle.

Carlos Maximiliano (2011, p. 204) indicava que "não se presumem, na lei, palavras inúteis", porque, ante a imperatividade inerente à norma jurídica, "devem se compreender as palavras como tendo alguma eficácia". O adágio é antigo e segue merecendo aplicação: verba cum effectu, sunt accipienda.

Sob essa premissa, não há como deixar de distinguir as observações, recomendações e ressalvas que o sistema atribui à competência do TCE-BA.

Mais ainda: considerando que recomendações e observações encerram conselhos de orientação, fundados no postulado da cooperação - que é inerente aos processos de controle público -, é consequência lógica disso que elas devem ter lugar quando exista irregularidade ou falha de menor gravidade, justificando-se sua aplicação para o aprimoramento, e não para a correção da gestão.

Cumpre rememorar, por oportuno e importante, que a resolução regimental que trata de conceitos para a matéria relativa a observações, recomendações e ressalvas é a de $n^{\circ} 12$, de 04 de março de 1993, ainda em vigor, que dispõe sobre as normas de procedimento para o controle externo da administração pública do estado.

Essa resolução ao definir regras para o trabalho maior desta Casa de Auditoria, que é a emissão do parecer prévio, assim dispõe em seu artigo $9^{\circ}$, in verbis:

Art. $9^{\circ} \mathrm{O}$ parecer prévio mesmo favorável à aprovação poderá conter observações, recomendações e ressalvas relativas, em ordem crescente, respectivamente, à gravidade dos atos contrários às normas de administração financeira, orçamentária e patrimonial e falhas cometidas na gestão dos programas governamentais (Grifo nosso). 
Portanto dúvidas não podem restar de que, além de terem conteúdos jurídicos distintos, as observações, recomendações e ressalvas devem ser apostas a uma opinião aprovativa, de acordo com a gravidade da restrição.

Nessa linha de pensar é que a citada Resolução n ${ }^{0} 12 / 1993$, ao abordar, em seu art. $10, \S 1^{\circ}$, sobre a aprovação de uma prestação de contas, nos termos dos artigos 121 e 122 do Regimento Interno, possibilita a aposição de observações, recomendações e ressalvas e que estas "são relativas, em ordem crescente, respectivamente, à gravidade dos atos contrários às normas de administração financeira, orçamentária e patrimonial das falhas cometidas na gestão dos programas governamentais".

De mais a mais, desde os idos de 2014, já havia a dispensa de notificação quando os auditores opinavam pela aprovação sem ressalvas. Com efeito, o art. 13 da Resolução no 192/20143, importante também registrar, estabelecia normas para prestações de contas dos jurisdicionados do Tribunal de Contas e confirmou a distinção quando coloca que, em se tratando de observações e recomendações, por isso mesmo não envolvem imputações de irregularidade gravosas, mas, sim, proposições para o aperfeiçoamento da administração, determinando, inclusive, que fosse dispensada a notificação dos responsáveis sobre o opinativo da Auditoria.

\section{DE UMA ANTIGA DISCUSSÃO}

Frise-se que quem primeiro inovou ao discutir esse tema objetivando melhor aclarar as distinções entre observações, recomendações e

3 Impende registrar que essa resolução objetivou acelerar a tramitação dos processos no Tribunal de Contas que há muito sofria e sofre com os gargalos nas suas apreciações. Mas também é devido registrar que a Resolução $n^{\circ}$ 82/2012, que aprova o Plano de Diretrizes do Tribunal de Contas do Estado da Bahia para o exercício de 2013, já sinalizava para a necessidade do TCE-BA ser mais célere, ao afirmar em seu art. 10 que: "Nos processos relativos a contas de ordenadores de despesas, administradores e Secretários de Estado ou dirigentes de órgãos diretamente subordinados ao Governador, bem como nos processos de prestação de contas de recursos estaduais atribuídos a municípios ou a entidades e instituições, em que o opinativo da unidade técnico-instrutória for pela aprovação, sem a indicação de recomendações e/ou ressalvas, o Ministério Publico Especial de Contas manifestar-se-á verbalmente, após a apresentação do relatório pelo Conselheiro Relator, nas sessões de julgamento do Tribunal Pleno e da Câmara, sem prejuízo do disposto no artigo n 106 do RITCE”. 


\section{Entrole}

ressalvas foi o conselheiro Antonio Honorato, quando foi relator das contas do chefe do Poder Executivo do estado da Bahia, exercício de 2009. Naquela oportunidade, assim se manifestou o eminente conselheiro:

A aprovação com recomendações, situação mais usual, deve ser sugerida quando forem constatadas situações que representem ocorrências sem muita guarida na gestão da coisa pública e que carecem de uma atenção especial da administração, de modo a melhorar as boas práticas de governança.

A aprovação com observações, raramente utilizada no âmbito deste Tribunal de Contas, também tem o seu lugar. Nada obstante a ausência de artigos acadêmicos ou posições interpretativas que deem ao seu conteúdo significado e significância, em uma análise dedutiva, pode-se afirmar que a aprovação com observações seria uma posição intermediária entre o aprovar com recomendações e o aprovar com ressalvas.

Assim será, se for possível proceder à devida dosimetria das constatações auditoriais. Como essa métrica nem sempre é possível, talvez daí decorra a pouca utilização dessa modalidade de opinar nos trabalhos auditoriais desta Casa de Controle.

Em um esforço de buscar um caminho, um trilhar, entende-se que a aprovação com observações é o aprovar com advertência, não suficientemente relevante para se configurar uma ressalva ou mesmo uma manifestação reprovativa, contudo representa uma leve censura, uma admoestação.

Por fim, o ressalvar. Uma opinião com ressalva significa que se encontrou divergência ou se defrontou com restrições tais que impediram a opinião plena - ou, no linguajar auditorial, opinião limpa - mas também não foram significantes (relevantes e materiais) ao ponto de ensejar uma opinião reprovativa (Bahia, 2010).

Registre-se, por derradeiro, que a doutrina especializada já avançou nessa questão, o que poderia ser considerado em uma necessária alteração regimental no âmbito deste TCE-BA, ao se referir como três as modalidades de manifestação conclusiva sobre as contas, pelos tribunais de contas: 
As contas julgadas regulares são aquelas que expressam, de forma clara e objetiva, a exatidão dos demonstrativos contábeis, a legalidade, a legitimidade e a economicidade dos atos de gestão. As contas regulares com ressalva são aquelas em que constam impropriedades ou qualquer outra falta de natureza formal, desde que não resulte dano ao Erário. Já as contas irregulares são aquelas de comprovadas situações que possam de alguma forma causar danos ao patrimônio público, como, por exemplo, infração à norma legal ou regulamentar de natureza contábil, financeira (Quintal et al., 2012, p. 37-38).

Esse entendimento vem sendo, desde há muito, aplicado na prática de tribunais de contas, que efetivamente direcionam a imputação de irregularidades, conforme a gravidade, ou bem à aprovação das contas com ressalvas, ou bem à reprovação das contas, reservando as observações, as recomendações e, como gênero, os conselhos de orientação para o aperfeiçoamento da gestão pública, mas não para as situações de falha financeira, orçamentária ou patrimonial.

Com base nessa posição doutrinária, poder-se-ia afirmar também que há três ${ }^{4}$ tipos possíveis de decisão por parte dos tribunais de contas. $\mathrm{O}$ aprovar, o aprovar com restrições e o desaprovar, sem se olvidar da possibilidade de se impor sanções pecuniárias como multas (compensatórias e indenizatórias) e ressarcimento de dano ao erário.

Como dito no introito deste artigo, essa é a posição majoritária das cortes de contas brasileiras, pois $90 \%$ dessas instituições assim procedem, sendo que $78 \%$ delas julgam os processos de contas como regulares, regulares com ressalva ou irregulares e que $12 \%$ dos tribunais de contas brasileiros julgam os processos de contas como regulares, regulares com ressalvas, irregulares e/ou iliquidáveis.

Contudo, no âmbito do TCE-BA, o aprovar com restrições abarca, à luz dos seus dispositivos normativos vigentes5, três espécies de aprovaContas do Estado da Bahia e dá outras providências; Resolução n ${ }^{\circ} 18$, de 29 de junho de 1992, que aprova o Regimento Interno do Tribunal de Contas do Estado da Bahia; Resolução $n^{\circ} 12 / 1993$, que dispõe sobre normas de procedimento para o controle externo da administração pública; e Resolução nº 149/2019, que dispõe sobre normas para 
ção: a com observações, a com recomendações e a com ressalvas. Portanto é preciso evoluir para melhor aclarar esses conceitos com objetividade e segurança jurídica, de modo a se definir, com a devida dosimetria, quais as hipóteses em que deve se aplicar cada caso.

\section{DA CONCLUSÃO}

Portanto, seja pela interpretação gramatical (que em rigor, aliás, não é interpretação, mas pressuposto para interpretação), seja pela interpretação lógico-sistemática, seja pela interpretação teleológica do art. 24 da Lei Orgânica do TCE e do art. 122 de seu Regimento Interno, deve-se concluir que as observações, recomendações e ressalvas são distintas e têm funções diversas de acordo com a gravidade das restrições impostas a um juízo opinativo pela aprovação de contas pelo Tribunal.

\section{REFERÊNCIAS}

ACRE. Lei Complementar $n^{\circ}$ 38, de 27 de dezembro de 1993. Dispõe sobre a Lei Orgânica do Tribunal de Contas do Estado do Acre e seu Ministério Público Especial, revoga a Lei Complementar Estadual $n^{\circ} 25$, de 14 de setembro de 1989, e dá outras providências. Rio Branco: Tribunal de Contas do Estado, 1993. Disponível em: https://bit.ly/36Y4Ibg. Acesso em: 20 maio 2020.

ACRE. Resolução TCE no 30, de 28 de novembro de 1996. Regimento Interno do Tribunal de Contas do Estado do Acre. Rio Branco: Tribunal de Contas do Estado, 1996. Disponível em: https://bit.ly/36Y4Ibg. Acesso em: 20 maio 2020.

prestação de contas pelos responsáveis por Unidades Jurisdicionadas da Administração Direta e Indireta Estadual para fins de julgamento pelo Tribunal de Contas do Estado da Bahia. 
ALAGOAS. Lei $\mathbf{n}^{\mathbf{0}}$ 5.604, de 20 de janeiro de 1994. Dispõe sobre a Lei Orgânica do Tribunal de Contas do Estado de Alagoas e dá outras providências. Maceió: Tribunal de Contas do Estado, 1994. Disponível em: https://bit.ly/33WZtGV. Acesso em: 20 maio 2020.

ALAGOAS. Resolução $\mathbf{n}^{\mathbf{0}} \mathbf{0 0 3} / \mathbf{2 0 0 1}$. Aprova o Regimento Interno do Tribunal de Contas do Estado de Alagoas. Maceió: Tribunal de Contas do Estado, 2001. Disponível em: https://bit.ly/36Y5RQ6. Acesso em: 20 maio 2020.

AMAPÁ. Lei Complementar $\mathbf{n}^{0}$ 10, de 20 de setembro de 1995. Institui a Lei Orgânica do Tribunal de Contas do Estado do Amapá e dá outras providências. Macapá: Tribunal de Contas do Estado do Amapá, 1995. Disponível em: https://bit.ly/2JLLc9c. Acesso em: 20 maio 2020.

AMAPÁ. Resolução Normativa n⿳ 115/2003-TCE/AP. Institui o Regimento Interno do Tribunal de Contas do Estado do Amapá. Macapá: Tribunal de Contas do Estado do Amapá, 2003. Disponível em: https://bit. 1y/3mTd3CC. Acesso em: 20 maio 2020.

AMAZONAS. Lei $\mathbf{n}^{\mathbf{0}} \mathbf{2 . 4 2 3}$, de 10 de dezembro de 1996. Lei Orgânica do Tribunal de Contas do Estado do Amazonas. Manaus: Tribunal de Contas do Estado do Amazonas, 1996. Disponível em: https://bit.ly/3mX1Vos. Acesso em: 20 maio 2020.

AMAZONAS. Resolução $\mathbf{n}^{\circ}$ 4, de 23 de maio de 2002. Dispõe sobre o Regimento Interno do Tribunal de Contas do Estado do Amazonas e do Ministério Público junto ao TCE-AM. Manaus: Tribunal de Contas do Estado do Amazonas, 2002. Disponível em: https://bit.ly/3grWGL5. Acesso em: 20 maio 2020. 
BAHIA. Lei Complementar $n^{0} 5$, de 4 de dezembro de 1991. Dispõe sobre a Lei Orgânica do Tribunal de Contas do Estado da Bahia. Salvador: Tribunal de Contas do Estado da Bahia, 1991a. Disponível em: https://bit. ly/3orQZPY. Acesso em: 19 maio 2020.

BAHIA. Lei Complementar $n^{0}$ 6, de 6 de dezembro de 1991. Dispõe sobre a Lei Orgânica do Tribunal de Contas dos Municípios do Estado da Bahia e dá outras providências. Salvador: Tribunal de Contas do Estado da Bahia, 1991b. Disponível em: https://bit.ly/3qI4sVU. Acesso em: 20 maio 2020.

BAHIA. Relatório e Parecer Prévio do TCE sobre as Contas do Poder Executivo do Estado da Bahia: exercício de 2009. Conselheiro-Relator Antonio Honorato. Salvador: Tribunal de Contas do Estado da Bahia, 2010. Disponível em: www.tce.ba.gov.br. Acesso em: 19 maio 2020.

BAHIA. Resolução no 18, de 29 de junho de 1992. Aprova o Regimento Interno do Tribunal de Contas do Estado da Bahia. Salvador: Tribunal de Contas do Estado da Bahia, 1992. Disponível em: https://bit.ly/2IyOZpS. Acesso em: 19 maio 2020.

BAHIA. Resolução $\mathbf{n}^{\mathbf{0}}$ 12, de 4 de março de 1993. Estabelece normas de procedimento para o controle externo da Administração Pública pelo Tribunal de Contas e dá outras providências. Salvador: Tribunal de Contas do Estado da Bahia, Disponível em: https://bit.ly/37GmI9i. Acesso em: 19 maio 2020.

BAHIA. Resolução no 82, de 30 de outubro de 2012. Aprova o Plano de Diretrizes do Tribunal de Contas do Estado da Bahia para o exercício de 2013 e dá outras providências. Salvador: Tribunal de Contas do Estado 
da Bahia, 2012. Disponível em: https://bit.ly/3mYVfWO. Acesso em: 19 maio 2020.

BAHIA. Resolução n⿳ 192, de 14 de outubro de 2014. Dispõe sobre normas para prestação de contas pelos responsáveis por Unidades Jurisdicionadas da Administração Direta e Indireta Estadual para fins de julgamento pelo Tribunal de Contas do Estado da Bahia. Salvador: Tribunal de Contas do Estado da Bahia, 2014. Disponível em: https://bit.ly/39SJMUR. Acesso em: 19 maio 2020.

BAHIA. Resolução n⿳ 149, de 31 de outubro de 2019. Dispõe sobre normas para prestação de contas pelos responsáveis por Unidades Jurisdicionadas da Administração Direta e Indireta Estadual para fins de julgamento pelo Tribunal de Contas do Estado da Bahia. Salvador: Tribunal de Contas do Estado da Bahia, 2019a. Disponível em: https://bit.ly/3oAsoZ8. Acesso em: 19 maio 2020.

BAHIA. Resolução no $\mathbf{n}^{\mathbf{1} .392 / 2019}$. Aprova o Regimento Interno do Tribunal de Contas dos Municípios do Estado da Bahia, e dá outras providências. Salvador: Tribunal de Contas do Estado da Bahia, 2019b. Disponível em: https://bit.ly/3gooBvk. Acesso em: 20 maio 2020.

BRASIL. Lei Federal no 8.443, de 16 de julho de 1992. Dispõe sobre a Lei Orgânica do Tribunal de Contas da União e dá outras providências. Brasília, DF, 1992. Disponível em: https://bit.ly/3qA8uj3. Acesso em: 20 maio 2020.

BRASIL. Resolução TCU n 246, de 30 de novembro de 2011. Altera o Regimento Interno do Tribunal de Contas da União, aprovado pela Resolução TCU no 155 , de 4 de dezembro de 2002. Brasília, DF: Tribunal de 
Contas da União, 2011. Disponível em: https://bit.ly/33Q2SHB. Acesso em: 20 maio 2020.

CEARÁ. Lei $\mathbf{n}^{0} \mathbf{1 2 . 5 0 9}$, de 6 de dezembro de 1995. Dispõe sobre a Lei Orgânica do Tribunal de Contas do Estado e dá outras providências. Fortaleza: Assembleia Legislativa do Estado do Ceará, 1995. Disponível em: https://bit.ly/36ZfPkq. Acesso em: 20 maio 2020.

CEARÁ. Resolução no 835, de 3 de abril de 2007. Aprova o Regimento Interno do Tribunal de Contas do Estado do Ceará. Fortaleza: Tribunal de Contas do Estado do Ceará, 2007. Disponível em: https://bit.ly/36XsIex. Acesso em: 20 maio 2020.

DISTRITO FEDERAL. Lei Complementar n ${ }^{0}$ 1, de 9 de maio de 1994. Dispõe sobre a Lei Orgânica do Tribunal de Contas do Distrito Federal e dá outras providências. Brasília, DF: Câmara Legislativa do Distrito Federal, 1994. Disponível em: https://bit.ly/2JDtEw4. Acesso em: 20 maio 2020.

DISTRITO FEDERAL. Resolução $\mathbf{n}^{\mathbf{0}}$ 296, de 15 de setembro de 2016. Aprova o Regimento Interno do Tribunal de Contas do Distrito Federal. Brasília, DF: Tribunal de Contas do Distrito Federal, 2016. Disponível em: https://bit.ly/2VUn8na. Acesso em: 20 maio 2020.

ESPÍRITO SANTO. Lei Complementar no 621, de 8 de março de 2012. Dispõe sobre a Lei Orgânica do Tribunal de Contas do Estado do Espírito Santo e dá outras providências. Vitória: Tribunal de Contas do Estado do Espírito Santo, 2012. Disponível em: https://bit.ly/2VWq6Hw. Acesso em: 20 maio 2020. 
ESPÍRITO SANTO. Resolução no 261, de 4 de junho de 2013. Aprova o Regimento Interno do Tribunal de Contas do Estado do Espírito Santo. Vitória: Tribunal de Contas do Estado do Espírito Santo, 2013. Disponível em: https://bit.ly/2JCON9D. Acesso em: 20 maio 2020.

GOIÁS. Lei $\mathbf{n}^{\mathbf{0}} \mathbf{1 5 . 9 5 8}$, de 18 de janeiro de 2007. Dispõe sobre a Lei Orgânica do Tribunal de Contas dos Municípios do Estado de Goiás e dá outras providências. Goiânia: Governo do Estado de Goiás, 2007a Disponível em: https://bit.ly/39WzXp0. Acesso em: 20 maio 2020.

GOIÁS. Lei $\mathbf{n}^{\mathbf{0}} \mathbf{1 6 . 1 6 8}$, de 11 de dezembro de 2007. Dispõe sobre a Lei Orgânica do Tribunal de Contas do Estado de Goiás. Goiânia: Governo do Estado de Goiás, 2007b. Disponível em: https://bit.ly/36XvrVx. Acesso em: 20 maio 2020.

GOIÁS. Resolução $\mathbf{n}^{\mathbf{0}}$ 22, de 2008. Regimento Interno do Tribunal de Contas de Goiás. Goiânia: Tribunal de Contas do Estado de Goiás, 2008. Disponível em: https://bit.ly/31YdGto. Acesso em: 20 maio 2020.

GOIÁS. Resolução Administrativa no 73, de 21 de outubro de 2009. Institui o Regimento Interno do Tribunal de Contas dos Municípios do Estado de Goiás. Goiânia: Tribunal de Contas do Estado de Goiás, 2009. Disponível em: https://bit.ly/33W4Xlk. Acesso em: 20 maio 2020.

INSTITUTO RUI BARBOSA. Normas Brasileiras de Auditoria do Setor Público (NBASP) - Nível 3. Curitiba: IRB, 2019. Disponível em: https://bit.ly/3qGmYOk. Acesso em: 19 maio 2020.

MARANHÃO. Resolução Administrativa no 1, de 21 de janeiro de 2000. Aprova o Regimento Interno do Tribunal de Contas. São Luís: 
Tribunal de Contas do Estado do Maranhão Disponível em: https://bit. ly/3gpB2Hj. Acesso em: 20 maio 2020.

MARANHÃO. Lei n⿳0 $\mathbf{8 . 2 5 8}$, de 6 de junho de 2005. Dispõe sobre a Lei Orgânica do Tribunal de Contas do Estado do Maranhão e dá outras providências. São Luís: Tribunal de Contas do Estado do Maranhão, 2005. Disponível em: https://bit.ly/3gpB2Hj. Acesso em: 20 maio 2020.

MATO GROSSO. Lei Complementar n⿳ 269, de 22 de janeiro de 2007. Dispõe sobre a Lei Orgânica do Tribunal de Contas do Estado de Mato Grosso e dá outras providências. Cuiabá: Assembleia Legislativa do Estado de Mato Grosso, 2007a. Disponível em: https://bit.ly/2VSe81w. Acesso em: 20 maio 2020.

MATO GROSSO. Resolução no 14, de 2 outubro de 2007. Institui o Regimento Interno do Tribunal de Contas, nos termos da Lei Complementar 269, de 29 de janeiro de 2007 - Lei Orgânica do Tribunal de Contas do Estado de Mato Grosso. Cuiabá: Tribunal de Contas do Estado de Mato Grosso, 2007b. Disponível em: https://bit.ly/2LaXpo6. Acesso em: 20 maio 2020.

MATO GROSSO DO SUL. Lei Complementar $\mathbf{n}^{\mathbf{0}} \mathbf{1 6 0}$, de 2 de janeiro de 2012. Dispõe sobre o Tribunal de Contas do Estado de Mato Grosso do Sul, e dá outras providências. Campo Grande: Tribunal de Contas do Estado de Mato Grosso do Sul, 2012. Disponível em: https://bit.ly/3mYyZfv. Acesso em: 20 maio 2020.

MATO GROSSO DO SUL. Resolução no 98, de 5 de dezembro de 2018. Regimento Interno do Tribunal de Contas do Estado de Mato Grosso do Sul. Campo Grande: Tribunal de Contas do Estado de Mato Grosso do Sul, 2018. Disponível em: https://bit.ly/33UFSXI. Acesso em: 20 maio 2020. 
MAXIMILIANO, C. Hermenêutica e aplicação do direito. 20. ed. Rio de Janeiro: Forense, 2011.

MINAS GERAIS. Lei Complementar n 102, de 17 de janeiro de 2008. Dispõe sobre a organização do Tribunal de Contas e dá outras providências. Belo Horizonte: Tribunal de Contas do Estado de Minas Gerais, 2008a. Disponível em: https://bit.ly/31YEHNt. Acesso em: 20 maio 2020.

MINAS GERAIS. Resolução $\mathbf{n}^{\mathbf{0}} \mathbf{1 2}$ /2008. Belo Horizonte: Tribunal de Contas do Estado de Minas Gerais, 2008b. Disponível em: https://bit. ly/2IriPwe. Acesso em: 20 maio 2020.

NIETZSCHE, F. Fragmentos póstumos no final de 1886: primavera de 1887. [S. 1.: s. n.], 1887. Disponível em: https://bit.ly/3oxYPHM. Acesso em: 19 maio 2020.

PARÁ. Ato $\mathbf{n}^{0}$ 63, de 17 de dezembro de 2012. Regimento Interno do Tribunal de Contas do Estado do Pará. Belém: Tribunal de Contas do Estado do Pará, 2012a. Disponível em: https://bit.ly/2W2okVf. Acesso em: 20 maio 2020.

PARÁ. Lei Complementar $\mathbf{n}^{\circ}$ 81, de 26 de abril de 2012. Dispõe sobre a Lei Orgânica do Tribunal de Contas do Estado do Pará e dá outras providências. Belém: Tribunal de Contas do Estado do Pará, 2012b. Disponível em: https://bit.ly/3oFbUiH. Acesso em: 20 maio 2020.

PARÁ. Ato no 16/2013. Dispõe sobre o Regimento Interno do Tribunal de Contas dos Municípios do Estado do Pará. Belém: Tribunal de Contas do Estado do Pará, 2013. Disponível em: https://bit.ly/33T594z. Acesso em: 20 maio 2020. 
PARÁ. Lei Complementar $\mathbf{n}^{0}$ 109, de 27 de dezembro de 2016. Dispõe sobre a Lei Orgânica do Tribunal de Contas dos Municípios do Estado do Pará. Belém: Tribunal de Contas do Estado do Pará, 2016. Disponível em: https://bit.ly/2W2okVf. Acesso em: 20 maio 2020.

PARAÍBA. Lei Complementar Estadual n 18, de 13 de julho de 1993. Dispõe sobre a Lei Orgânica do Tribunal de Contas do Estado e dá outras providências. João Pessoa: Tribunal de Contas do Estado da Paraíba, 1993. Disponível em: https://bit.ly/37R5g1I. Acesso em: 20 maio 2020.

PARAÍBA. Resolução Normativa TC $\mathbf{n}^{\mathbf{0}}$ 10/2010. Regimento Interno do TCE-PB. João Pessoa: Tribunal de Contas do Estado da Paraíba, 2010. Disponível em: https://bit.ly/3oC6CEm. Acesso em: 20 maio 2020.

PARANÁ. Lei Complementar $n^{0}$ 113, de 15 de dezembro de 2005. Dispõe sobre a Lei Orgânica do Tribunal de Contas do Estado do Paraná. Curitiba: Tribunal de Contas do Estado do Paraná, 2005. Disponível em: https://bit.ly/2VVjucr. Acesso em: 20 maio 2020.

PARANÁ. Resolução no 1 , de 24 de janeiro de 2006. Aprova o Regimento Interno do Tribunal de Contas do Estado do Paraná. Curitiba: Tribunal de Contas do Estado do Paraná, 2006. Disponível em: https://bit.ly/3qFrBbl. Acesso em: 20 maio 2020.

PERNAMBUCO. Lei $\mathbf{n}^{\mathbf{0}} \mathbf{1 2 . 6 0 0}$, de 14 de junho de 2004. Dispõe sobre a Lei Orgânica do Tribunal de Contas do Estado de Pernambuco. Recife: Tribunal de Contas do Estado de Pernambuco, 2004. Disponível em: https://bit.ly/2Llka97. Acesso em: 20 maio 2020. 
PERNAMBUCO. Resolução TC $\mathbf{n}^{0}$ 15, de 10 de novembro de 2010. Institui o Regimento Interno do Tribunal de Contas do Estado de Pernambuco. Recife: Tribunal de Contas do Estado de Pernambuco, 2010. Disponível em: https://bit.ly/33WOxsM. Acesso em: 20 maio 2020.

PIAUÍ. Lei no 5.888 , de 19 de agosto de 2009. Dispõe sobre a Lei Orgânica do Tribunal de Contas do Estado do Piauí. Teresina: Tribunal de Contas do Estado do Piauí, 2009. Disponível em: https://bit.ly/31ZrzHP. Acesso em: 20 maio 2020.

PIAUÍ. Resolução TCE/PI no 13, de 26 de agosto de 2011. Regimento Interno do Tribunal de Contas do Estado do Piauí. Teresina: Tribunal de Contas do Estado do Piauí, 2011. Disponível em: https://bit.ly/3oFkqOH. Acesso em: 20 maio 2020.

QUINTAL, R. S. et al. A atuação dos tribunais de contas estaduais brasileiros na correção das demonstrações contábeis dos processos de prestação de contas dos governadores. Cadernos Gestão Pública e Cidadania, São Paulo, v. 17, n. 60, p. 31-53, 2012.

RONDÔNIA. Lei Complementar $\mathbf{n}^{0} \mathbf{1 5 4} / \mathbf{1 9 9 6}$. Dispõe sobre a Lei Orgânica do Tribunal de Contas do Estado de Rondônia, e dá outras providências. Porto Velho: Tribunal de Contas do Estado de Rondônia, 1996a. Disponível em: https://bit.ly/2W2A2PH. Acesso em: 20 maio 2020.

RONDÔNIA. Tribunal de Contas do Estado. Resolução Administrativa $\mathbf{n}^{0}$ 005/1996. Aprova o Regimento Interno do Tribunal de Contas do Estado de Rondônia. Porto Velho: Tribunal de Contas do Estado de Rondônia,1996b. Disponível em: https://bit.ly/37Muxdz. Acesso em: 20 maio 2020. 
RORAIMA. Lei Complementar Estadual no 6, de 6 de junho de 1994. Dispõe sobre a Lei Orgânica do Tribunal de Contas do Estado de Roraima e dá outras providências. Boa Vista: Tribunal de Contas do Estado de Roraima, 1994. Disponível em: https://bit.ly/37OiQ67. Acesso em: 20 maio 2020.

\section{RORAIMA. Regimento Interno do Tribunal de Contas do Estado de} Roraima. Boa Vista: Tribunal de Contas do Estado de Roraima, 2020. Disponível em: https://bit.ly/2KaVE9V. Acesso em: 20 maio 2020.

RIO DE JANEIRO. Lei $\mathbf{n}^{\mathbf{0}} \mathbf{2 8 9}$, de 25 de novembro de 1981. Regula a organização do Tribunal de Contas do Município do Rio de Janeiro e dá outras providências. Rio de Janeiro: Tribunal de Contas do Estado do Rio de Janeiro, 1981. Disponível em: https://bit.ly/2IvIN1H. Acesso em: 20 maio 2020 .

RIO DE JANEIRO. Lei Complementar $\mathbf{n}^{\mathbf{0}} \mathbf{6 3}$, de $^{\mathbf{0}}$ de agosto de 1990. Dispõe sobre a lei orgânica do Tribunal de Contas do Estado do Rio de Janeiro e dá outras providências. Rio de Janeiro: Tribunal de Contas do Estado do Rio de Janeiro, 1990. Disponível em: https:/bit.ly/39Uj66h. Acesso em: 20 maio 2020.

RIO DE JANEIRO. Deliberação $\mathbf{n}^{0}$ 167, de 10 de dezembro de 1992. Aprova o Regimento Interno do Tribunal de Contas do Estado do Rio de Janeiro. Rio de Janeiro: Tribunal de Contas do Estado do Rio de Janeiro, 1992. Disponível em: https://bit.ly/39Uj66h. Acesso em: 20 maio 2020.

RIO DE JANEIRO. Deliberação no $\mathbf{2 6 6}$, de 28 de maio de 2019. Aprova o Novo Regimento Interno do Tribunal de Contas do Município do Rio de Janeiro. Rio de Janeiro: Tribunal de Contas do Estado do Rio de Janeiro, 2019. Disponível em: https://bit.ly/3qBWFc9. Acesso em: 20 maio 2020. 
RIO GRANDE DO NORTE. Lei Complementar $n^{\mathbf{0}}$ 464, de 5 de janeiro de 2012. Dispõe sobre a Lei Orgânica do Tribunal de Contas do Estado do Rio Grande Norte. Natal: Tribunal de Contas do Estado do Rio Grande do Norte, 2012a. Disponível em: https://bit.ly/3qGeK8R. Acesso em: 20 maio 2020.

RIO GRANDE DO NORTE. Resolução no 9/2012. Dispõe sobre a aprovação do Regimento Interno do Tribunal de Contas do Estado do Rio Grande do Norte. Natal: Tribunal de Contas do Estado do Rio Grande do Norte, 2012b. Disponível em: https://bit.ly/2IvRU2x. Acesso em: 20 maio 2020.

RIO GRANDE DO SUL. Lei n⿳ 11.424, de 6 de janeiro de 2000. Dispõe sobre a Lei Orgânica do Tribunal de Contas do Estado. Porto Alegre: Tribunal de Contas do Estado do Rio Grande do Sul, 2000. Disponível em: https://bit.ly/3mVEWtP. Acesso em: 20 maio 2020.

RIO GRANDE DO SUL. Resolução n⿳ 1.028/2015. Aprova o Regimento Interno do Tribunal de Contas do Estado. Porto Alegre: Tribunal de Contas do Estado do Rio Grande do Sul, 2015. Disponível em: https://bit. ly/3n2dKcP. Acesso em: 20 maio 2020.

SANTA CATARINA. Lei Complementar $\mathbf{n}^{\mathbf{0}} \mathbf{2 0 2}$, de 15 de dezembro de 2000. Institui a Lei Orgânica do Tribunal de Contas do Estado de Santa Catarina e adota outras providências. Florianópolis: Tribunal de Contas do Estado de Santa Catarina, 2000. Disponível em: https://bit.ly/31ZSEL4. Acesso em: 20 maio 2020.

SANTA CATARINA. Tribunal de Contas do Estado. Resolução no TC6/2001. Institui o Regimento Interno do Tribunal de Contas do Estado de Santa Catarina. Florianópolis: Tribunal de Contas do Estado de Santa 
Catarina, 2001. Disponível em: https://bit.ly/39W9SXm. Acesso em: 20 maio 2020 .

SÃO PAULO. Lei no ${ }^{\circ}$ 9.167, de 3 de dezembro de 1980. Dispõe sobre a reorganização, competência, jurisdição e funcionamento do Tribunal de Contas do Município de São Paulo, e dá outras providências. São Paulo: Tribunal de Contas do Estado de São Paulo, 1980. Disponível em: https:// bit.ly/2Iywn9q. Acesso em: 20 maio 2020.

SÃO PAULO. Lei Complementar $\mathbf{n}^{0}$ 709, de 14 de janeiro de 1993. Dispõe sobre a Lei Orgânica do Tribunal de Contas do Estado. São Paulo: Tribunal de Contas do Estado de São Paulo, 1993. Disponível em: https:// bit.ly/37MyEq1. Acesso em: 20 maio 2020.

SÃO PAULO. Resolução no $\mathbf{3}$, de 3 de julho de 2002. Aprova o Regimento Interno do Tribunal de Contas do Município de São Paulo. São Paulo: Tribunal de Contas do Estado de São Paulo, 2002. Disponível em: https://bit.ly/33WnC06. Acesso em: 20 maio 2020.

SÃO PAULO. Regimento Interno do Tribunal de Contas do Estado de São Paulo. São Paulo: Tribunal de Contas do Estado de São Paulo, 2020. Disponível em: https://bit.ly/2VYLTyi. Acesso em: 20 maio 2020.

SERGIPE. Lei Complementar $\mathbf{n}^{\mathbf{0}}$ 205, de 6 de julho de 2011. Institui a Lei Orgânica do Tribunal de Contas do Estado de Sergipe, e dá providências correlatas. Aracaju: Tribunal de Contas do Estado se Sergipe, 2011. Disponível em: https://bit.ly/3gs50dH. Acesso em: 20 maio 2020.

SERGIPE. Regimento Interno do Tribunal de Contas do Estado de Sergipe. Aracaju: Tribunal de Contas do Estado se Sergipe, 2020. Disponível em: https://bit.ly/37RR7Sh. Acesso em: 20 maio 2020. 
TOCANTINS. Lei $\mathbf{n}^{\mathbf{0}} \mathbf{1 . 2 8 4}$, de 17 de dezembro de 2001. Dispõe sobre a Lei Orgânica do Tribunal de Contas do Estado do Tocantins. Palmas: Tribunal de Contas do Estado do Tocantins, 2001. Disponível em: https:// bit.ly/33WreiG. Acesso em: 20 maio 2020.

TOCANTINS. Resolução Normativa $n^{0}$ 2, de 4 de dezembro de 2002. Aprova o Regimento Interno do Tribunal de Contas do Estado do Tocantins. Palmas: Tribunal de Contas do Estado do Tocantins, 2002. Disponível em: https://bit.ly/36ZV6wP. Acesso em: 20 maio 2020. 
Entrole

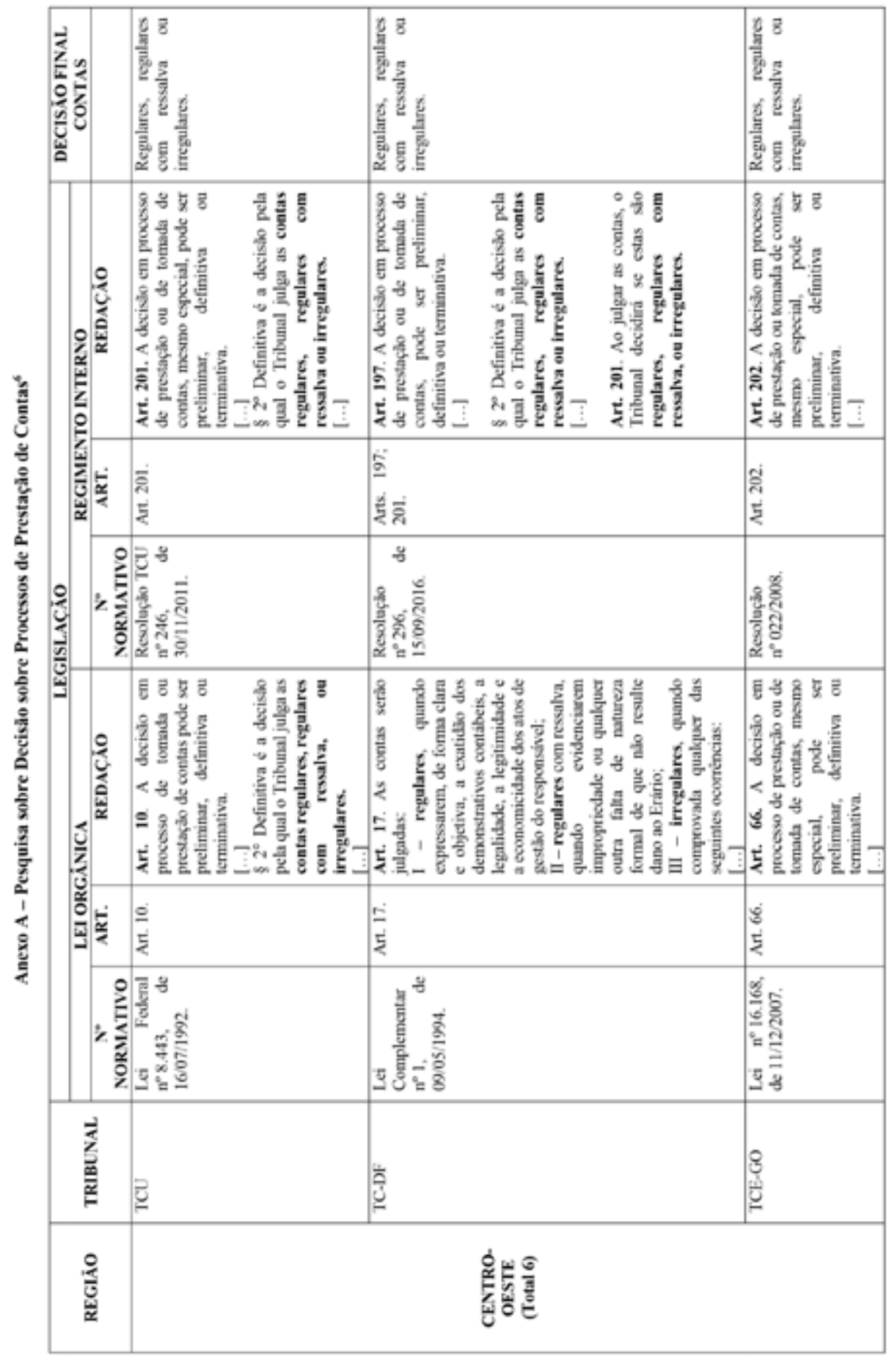

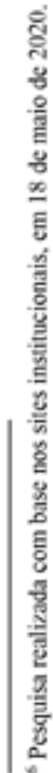

Rev. Controle, Fortaleza, v. 19, n.1, p. 39-81, jan./jun. 2021. 


\begin{tabular}{|c|c|c|c|c|}
\hline 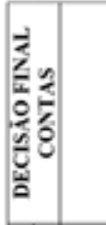 & & 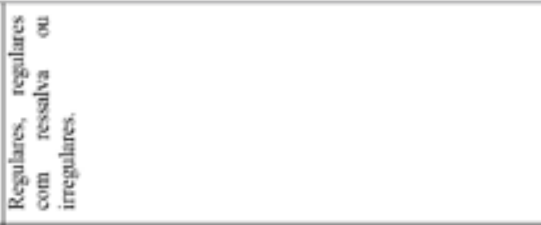 & 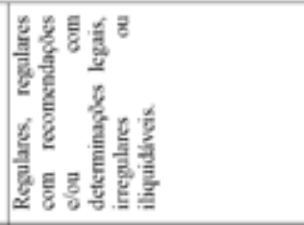 & 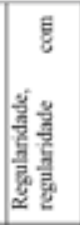 \\
\hline 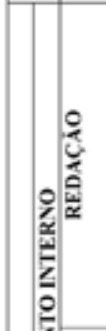 & 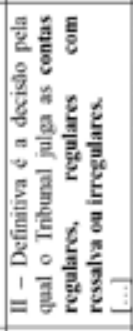 & 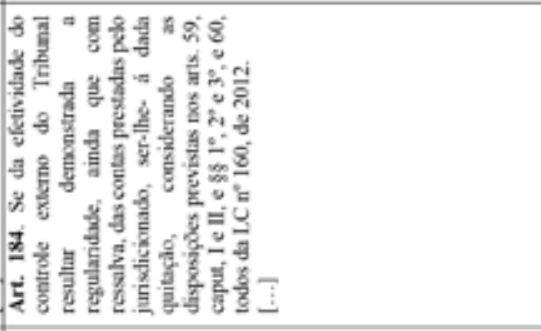 & 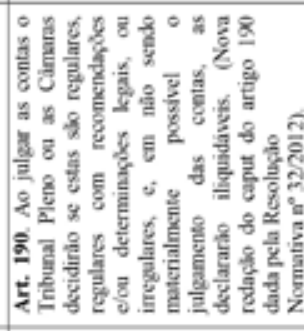 & 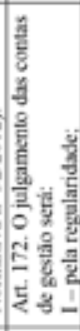 \\
\hline 这 & & & $\frac{8}{5}$ & 量 \\
\hline 资 & & 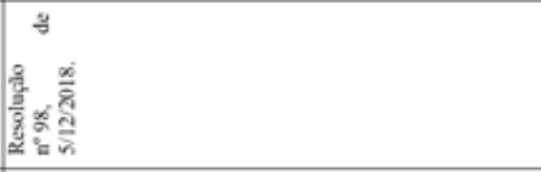 & 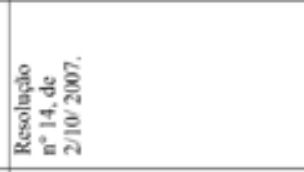 & 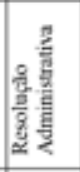 \\
\hline 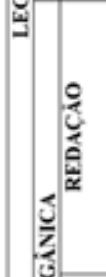 & 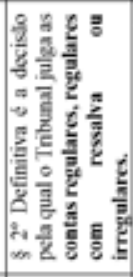 & 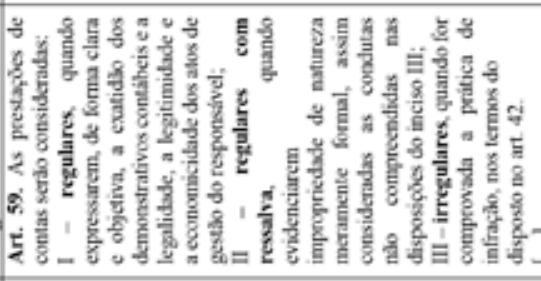 & 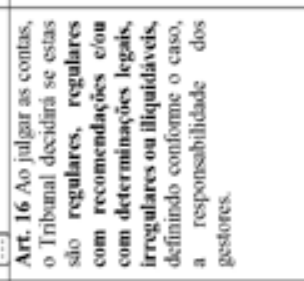 & 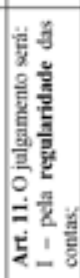 \\
\hline$\frac{2}{2}$ & & $\begin{array}{l}\text { में } \\
\text { है }\end{array}$ & $\frac{\mathscr{3}}{\underline{\Sigma}}$ & $\begin{array}{l}= \\
\text { ¿ } \mathrm{i}\end{array}$ \\
\hline 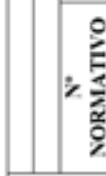 & & 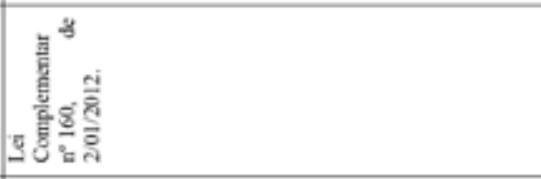 & 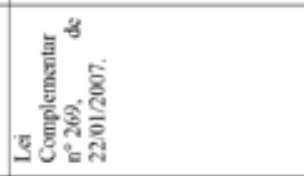 & 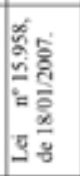 \\
\hline 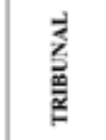 & & $\begin{array}{l}\frac{\hat{n}}{2} \\
\hat{2} \\
\hat{B}\end{array}$ & 位 & $\begin{array}{l}\frac{1}{3} \\
\frac{1}{2}\end{array}$ \\
\hline 递 & & & & \\
\hline
\end{tabular}




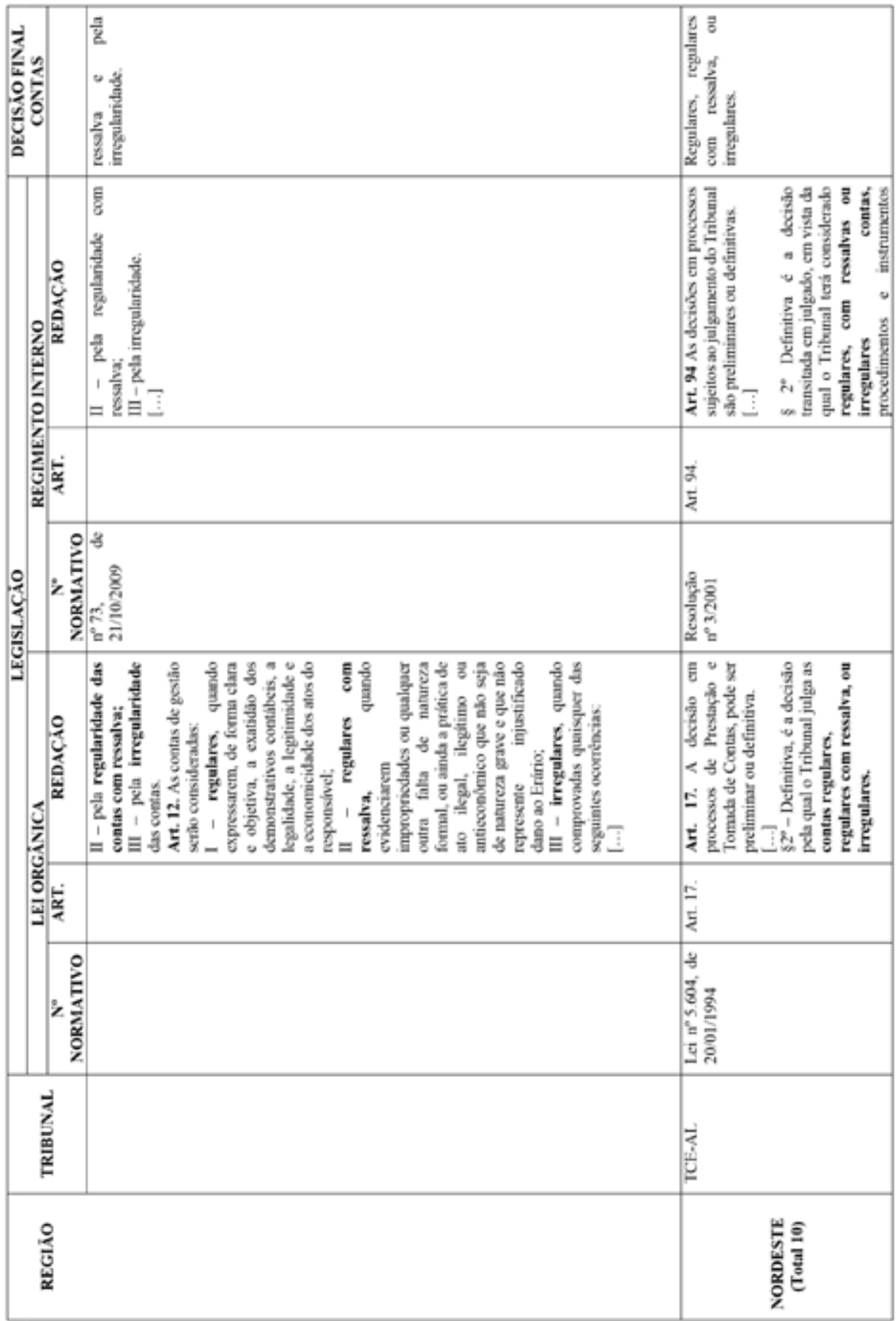

Rev. Controle, Fortaleza, v. 19, n.1, p. 39-81, jan./jun. 2021. 


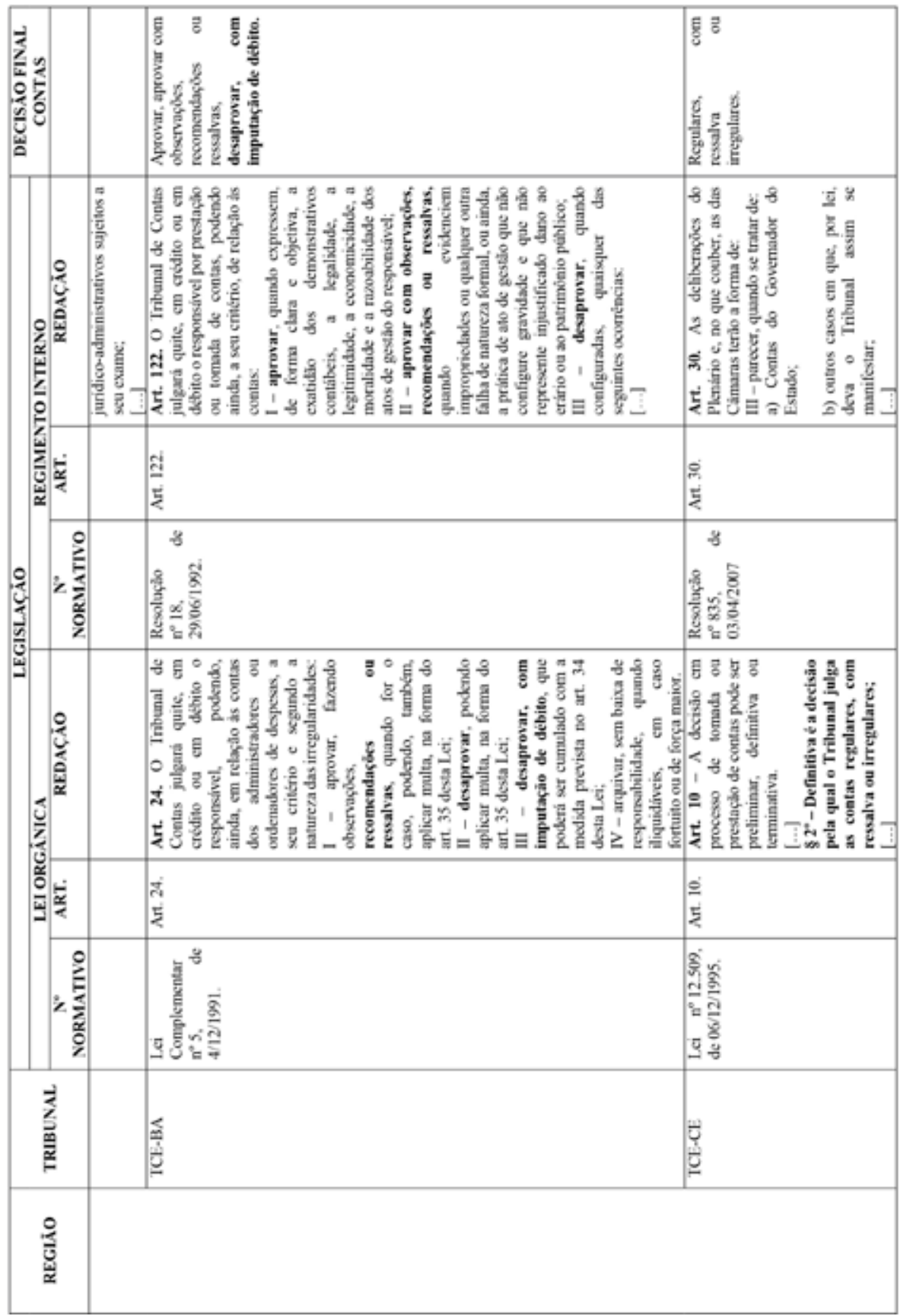




\begin{tabular}{|c|c|c|c|c|}
\hline 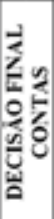 & & & 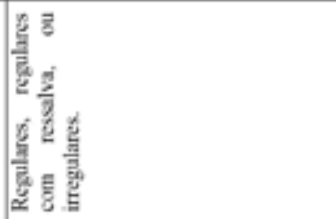 & 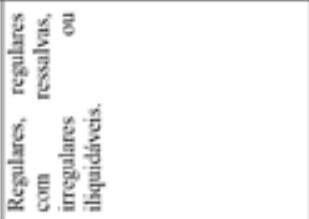 \\
\hline $\begin{array}{l}\frac{0}{2} \\
\frac{8}{2} \\
\frac{1}{2} \\
\frac{1}{2}\end{array}$ & ?ִ. & 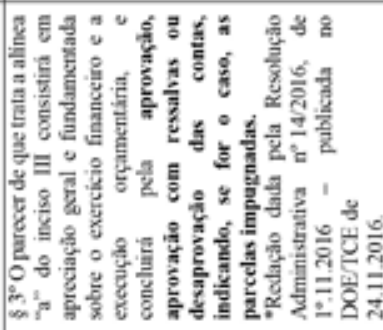 & 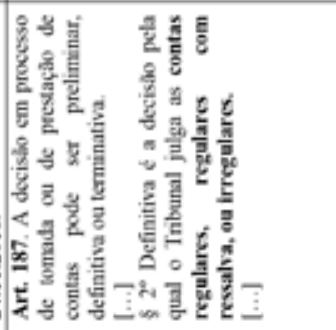 & 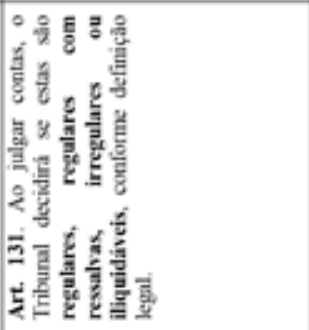 \\
\hline & $\frac{x}{2}$ & & $\frac{\mathscr{x}}{\tilde{z}}$ & $\frac{5}{5}$ \\
\hline & $<\frac{0}{2}$ & & 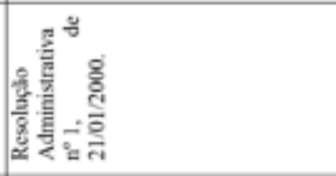 & 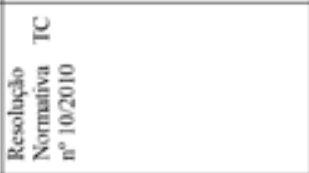 \\
\hline 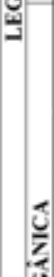 & בُ & & 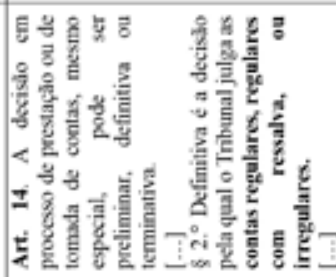 & 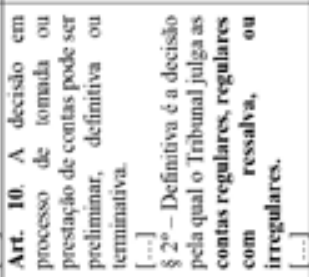 \\
\hline & $\frac{\dot{x}}{2}$ & & $\frac{ \pm}{E}$ & $\frac{\varrho}{5}$ \\
\hline & $\geqslant \frac{\varrho}{\frac{2}{2}}$ & & 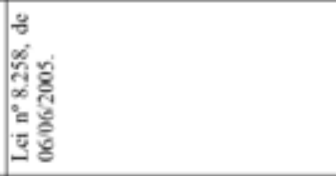 & छ \\
\hline & $\frac{\vec{z}}{\frac{\partial}{2}}$ & & 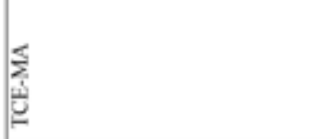 & 产 \\
\hline & & & & \\
\hline
\end{tabular}

Rev. Controle, Fortaleza, v. 19, n.1, p. 39-81, jan./jun. 2021. 


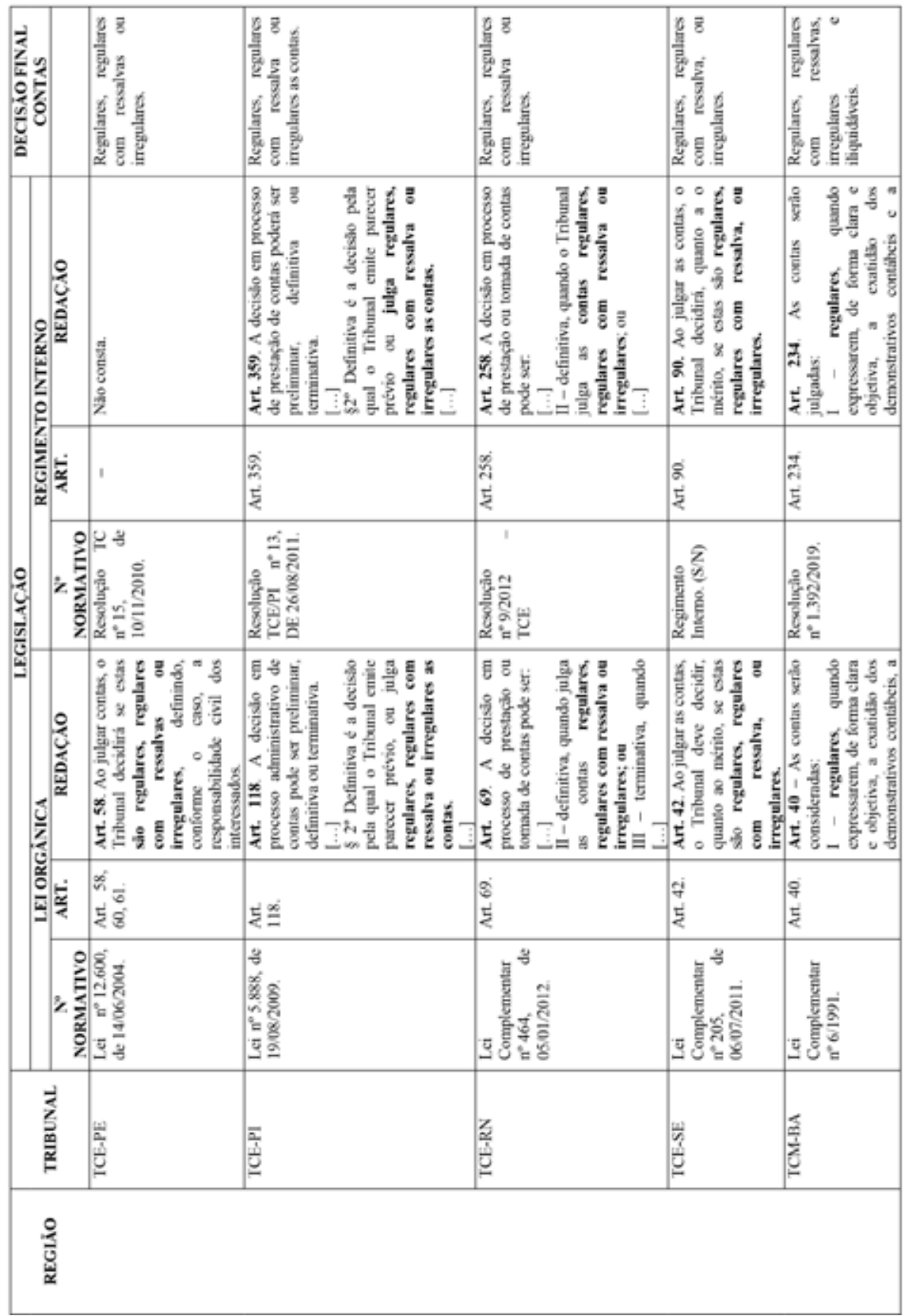




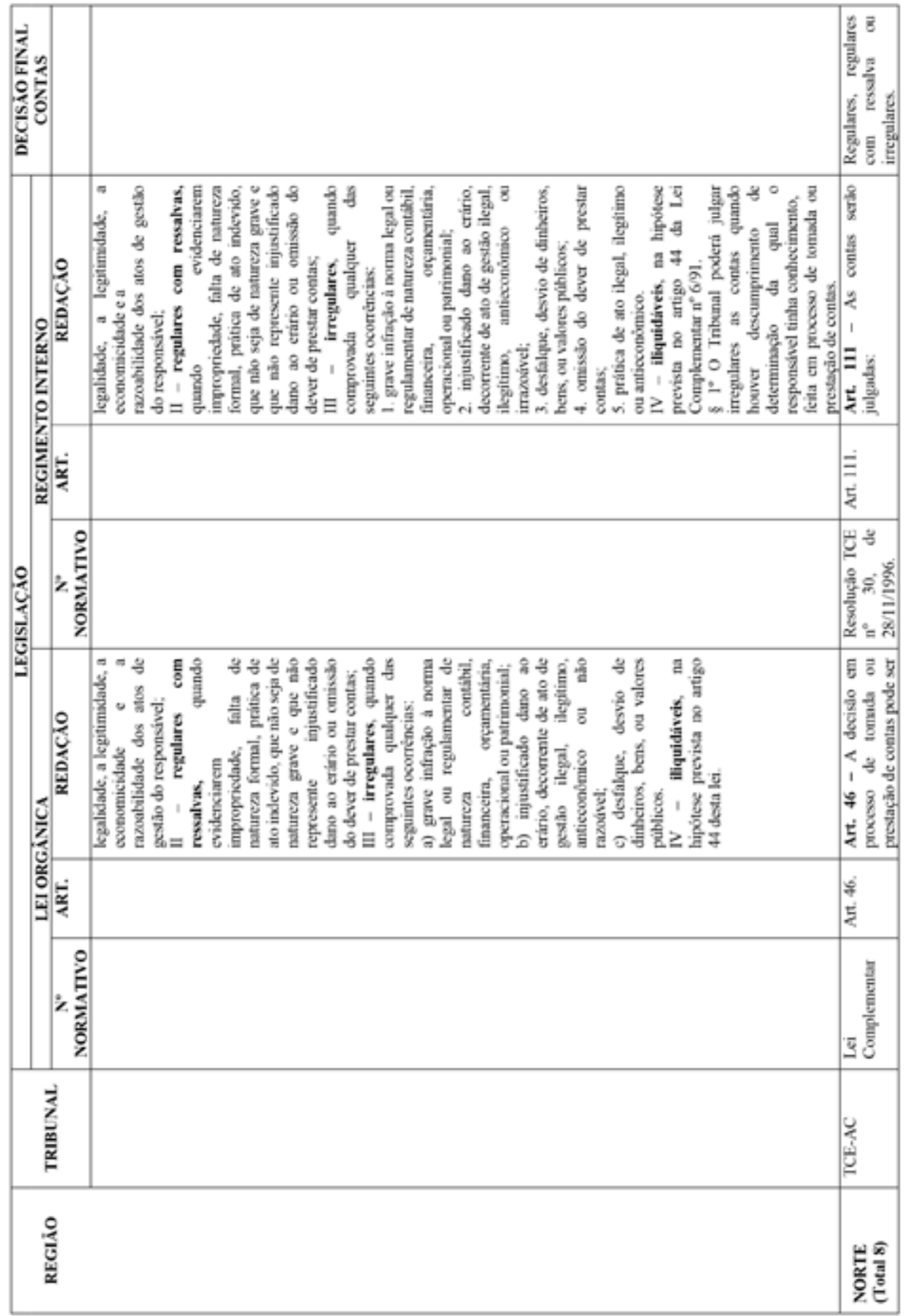

Rev. Controle, Fortaleza, v. 19, n.1, p. 39-81, jan./jun. 2021. 


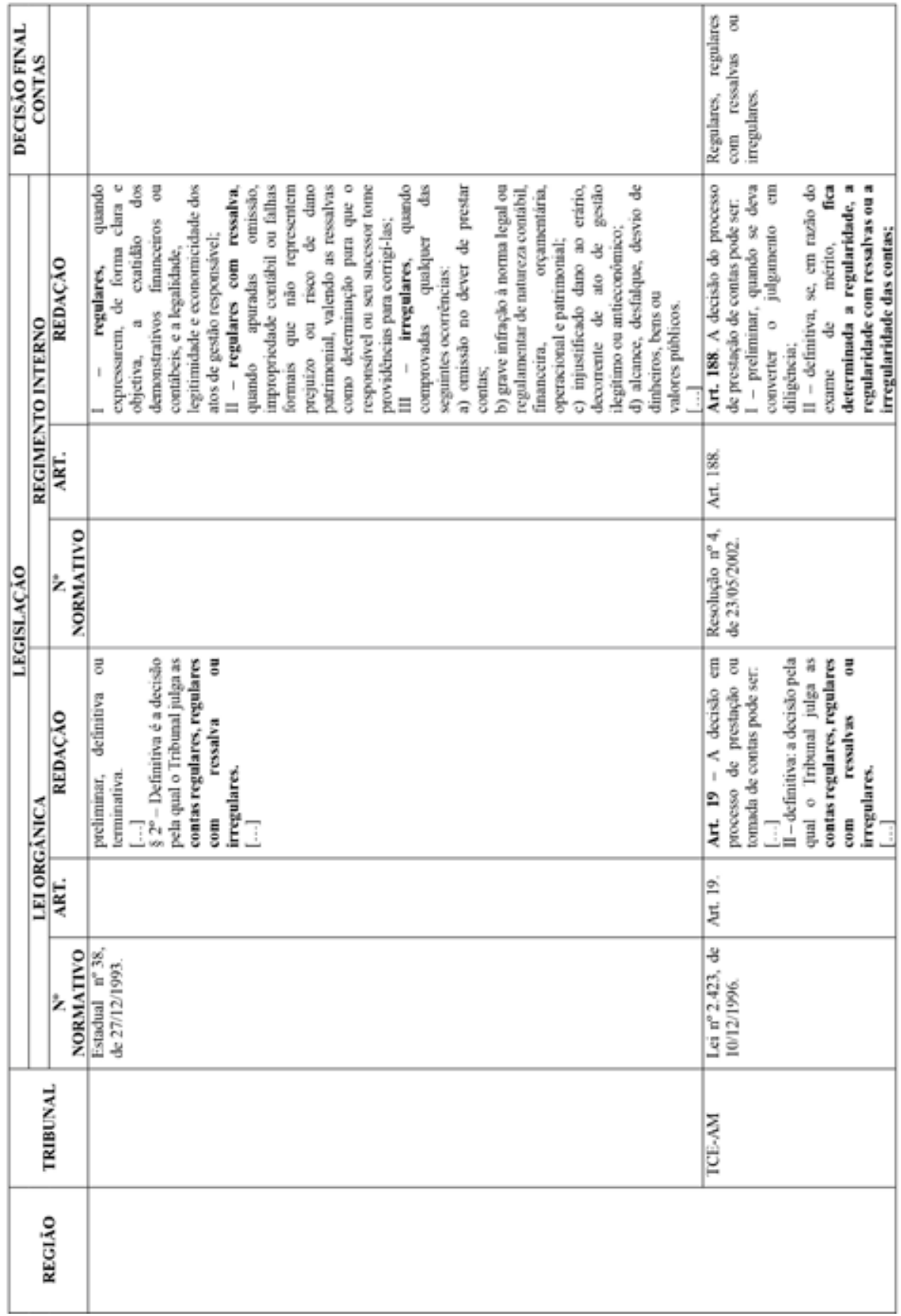




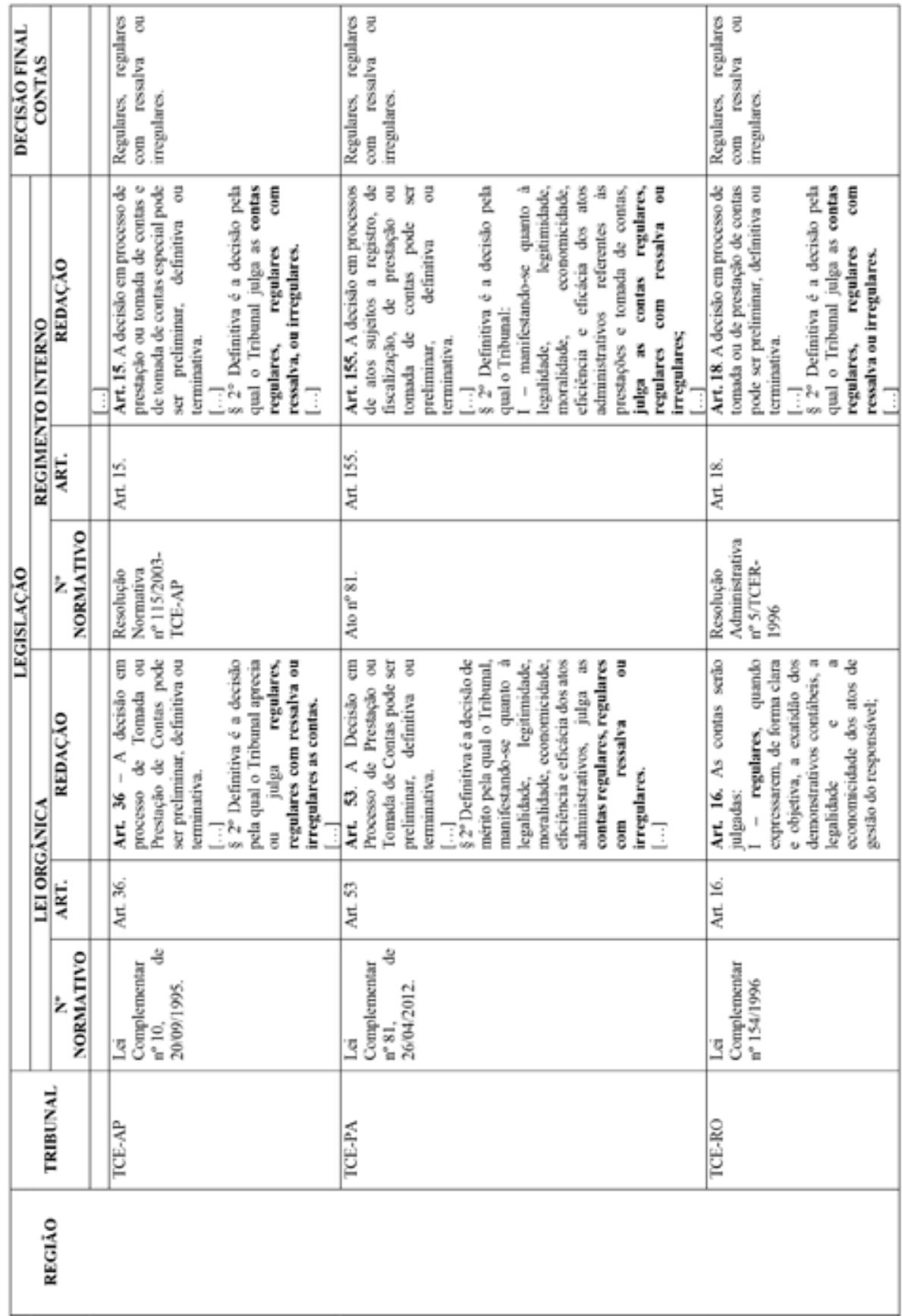

Rev. Controle, Fortaleza, v. 19, n.1, p. 39-81, jan./jun. 2021. 


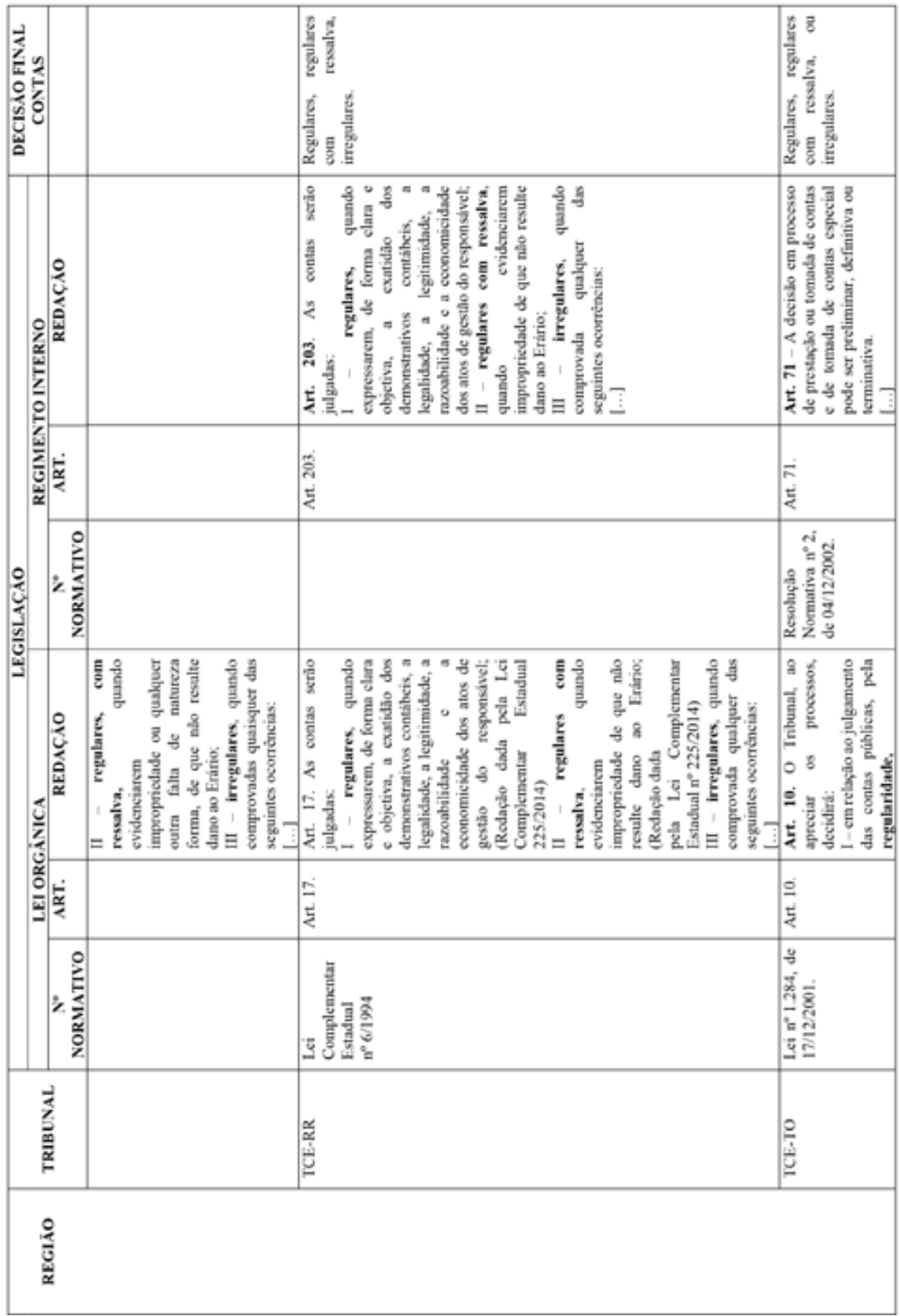




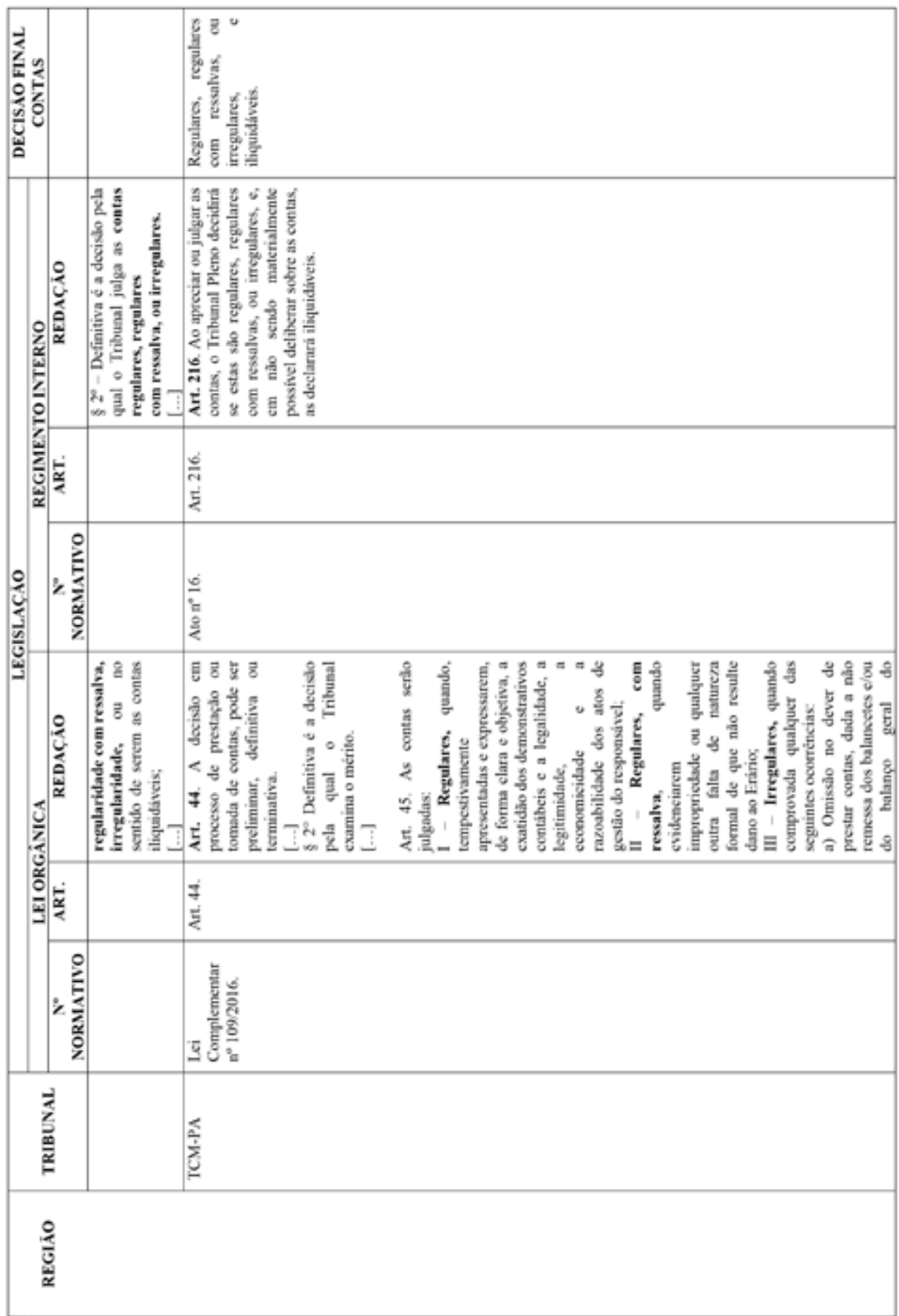

Rev. Controle, Fortaleza, v. 19, n.1, p. 39-81, jan./jun. 2021. 


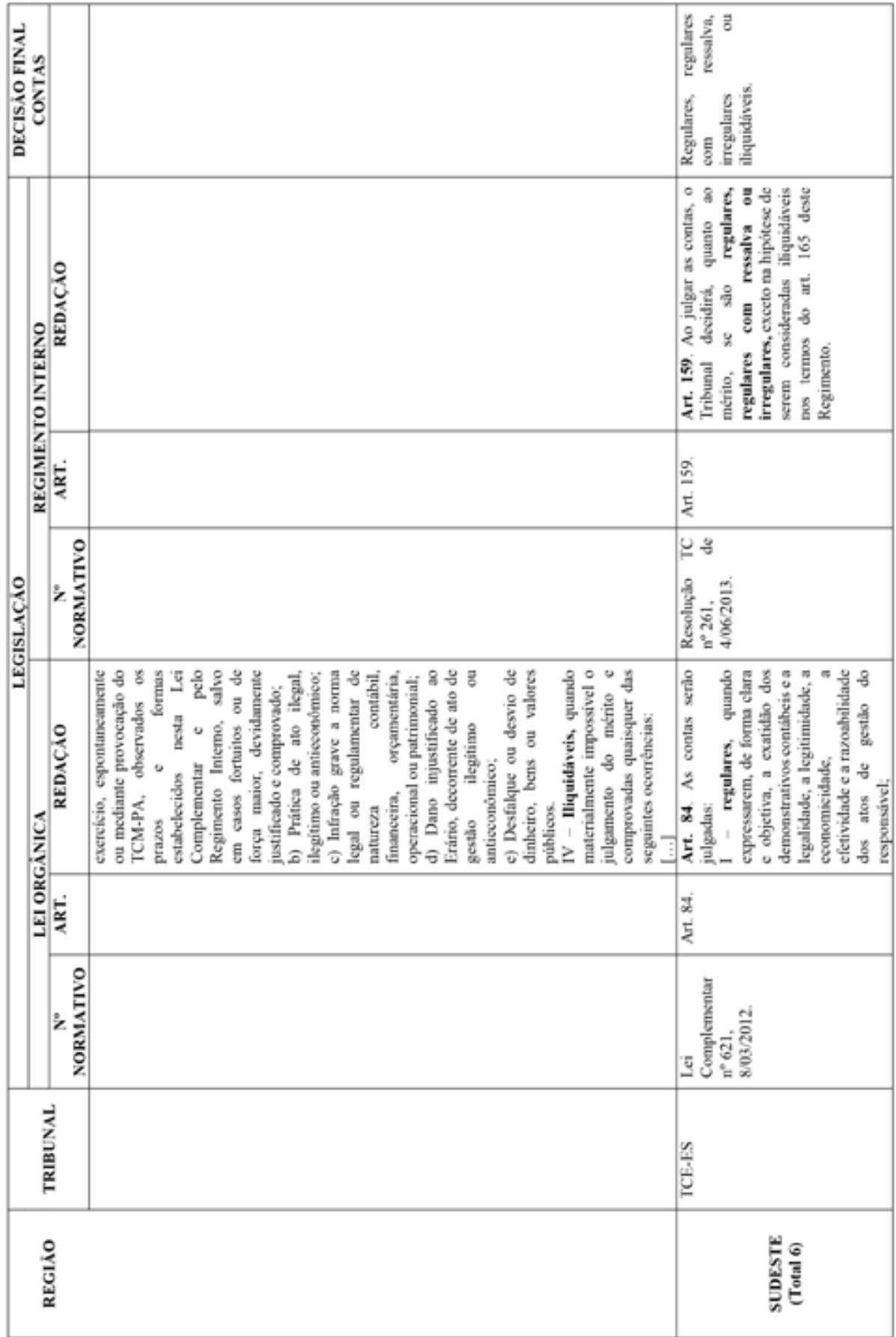




\begin{tabular}{|c|c|c|c|c|}
\hline 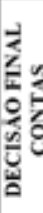 & & & 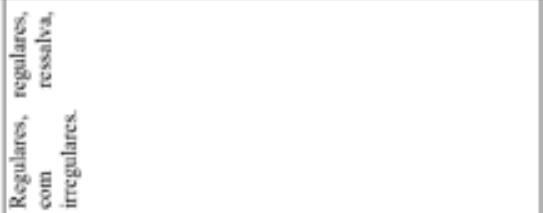 & 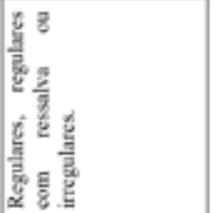 \\
\hline 8 & 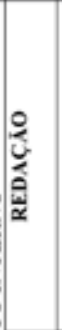 & & 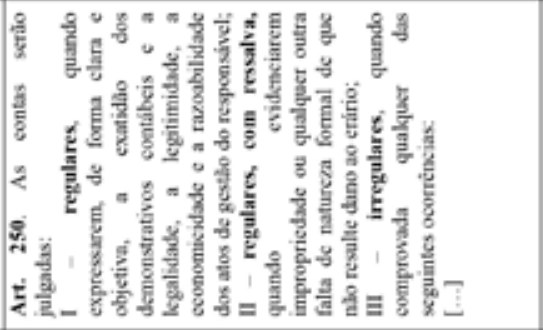 & 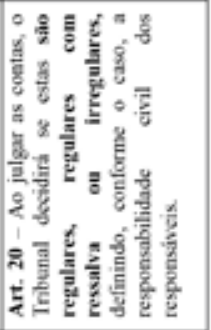 \\
\hline & $\stackrel{2}{2}$ & & 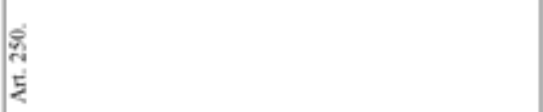 & 究 \\
\hline 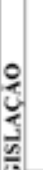 & 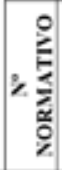 & & 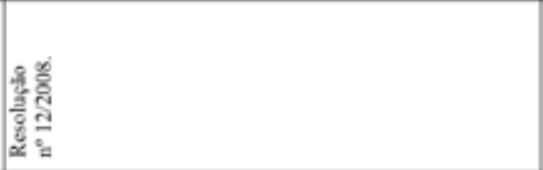 & $\frac{\sqrt{3}}{\frac{8}{2}} \frac{8}{8}$ \\
\hline 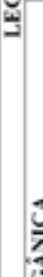 & 象 & 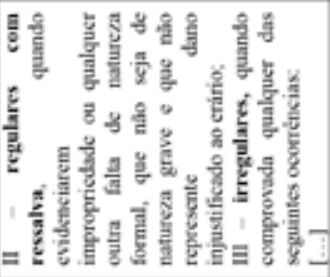 & 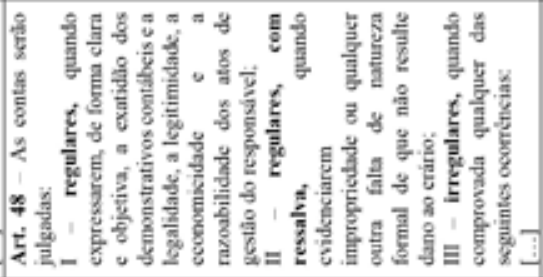 & 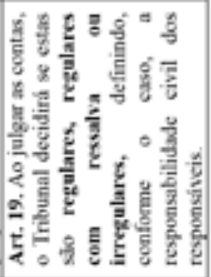 \\
\hline & $\dot{\vec{\alpha}}$ & & $\frac{x}{2}$ & $\frac{a}{\dot{z}}$ \\
\hline & $\frac{0}{2}$ & & 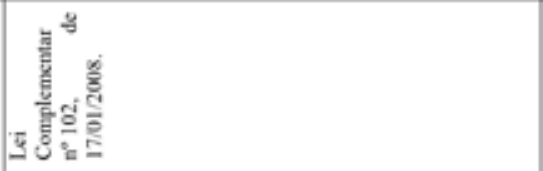 & 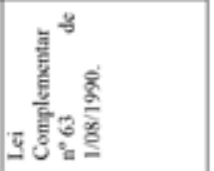 \\
\hline & 产 & & 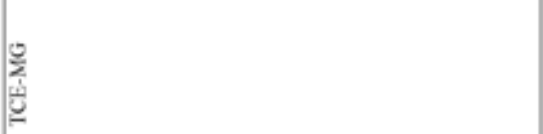 & $\frac{2}{4}$ \\
\hline & 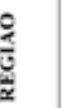 & & & \\
\hline
\end{tabular}

Rev. Controle, Fortaleza, v. 19, n.1, p. 39-81, jan./jun. 2021. 


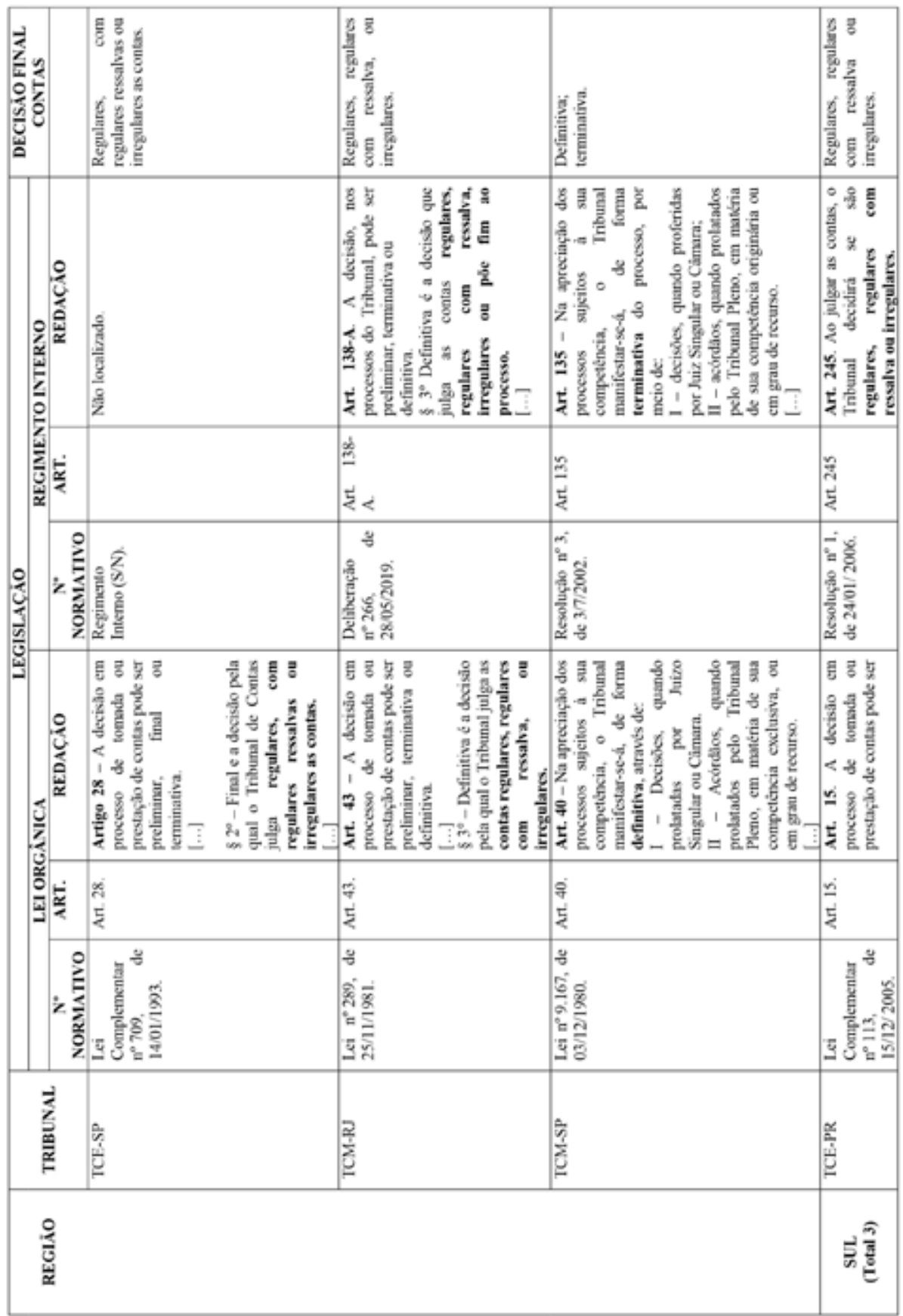




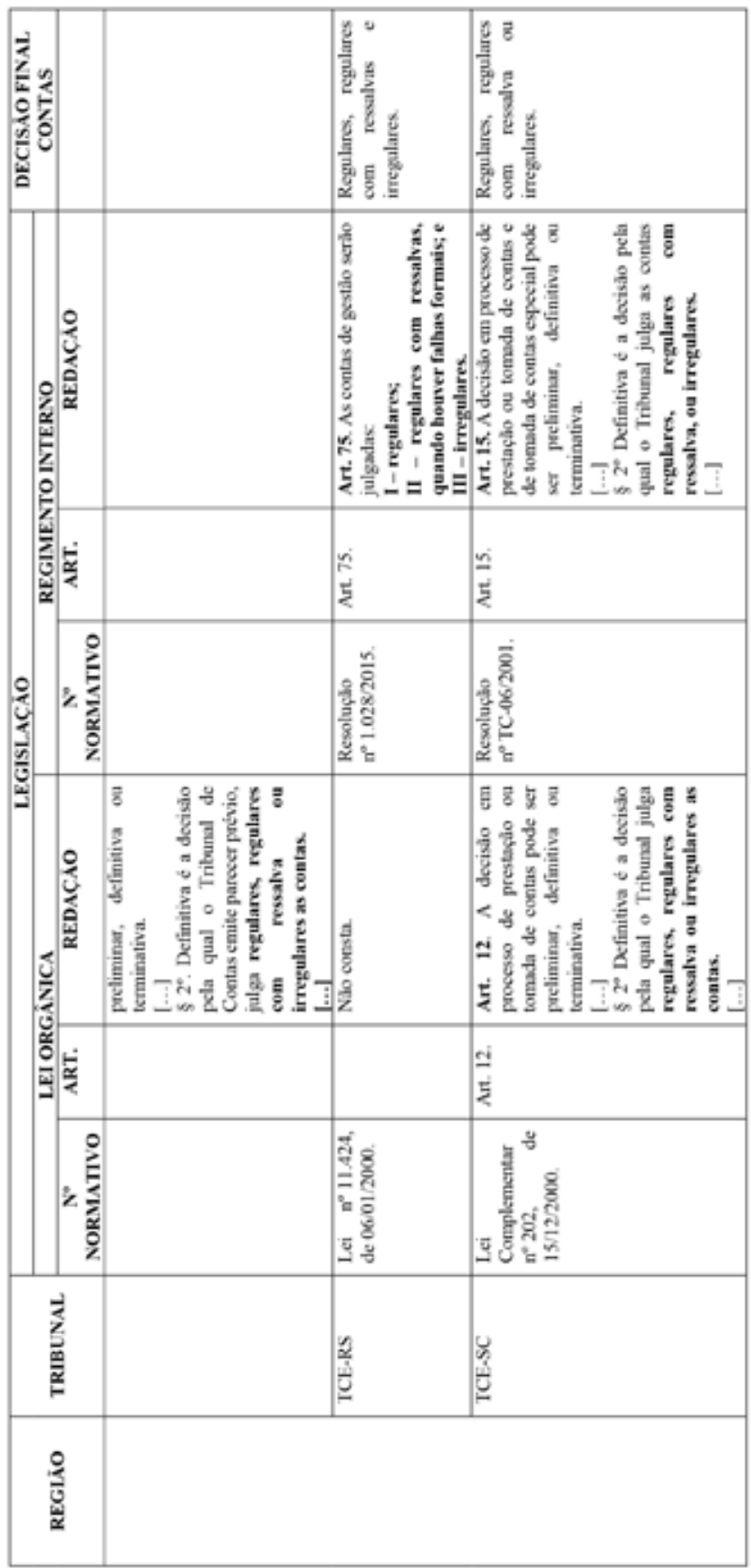

Rev. Controle, Fortaleza, v. 19, n.1, p. 39-81, jan./jun. 2021. 